Martin Auer

\title{
Municipium Claudium Aguntum - Zur Datierungsfrage der Stadtmauer
}

\section{Einleitung}

Die römischen Ruinen in der Umgebung von Lienz in Osttirol sind seit dem 16. Jahrhundert n. Chr. bekannt und sind auch in Reiseberichten beschrieben worden ${ }^{1}$. Die endgültige Identifizierung gelang 1873 Theodor Mommsen, der in ihnen das antike Municipium Claudium Aguntum erkannte ${ }^{2}$. Auf Grundlage umfangreicher theoretischer Vorarbeit von Adolf B. Meyer und August Unterforcher ${ }^{3}$ fanden in den Jahren 1912-1913 erste archäologische Grabungen durch Innozenz Ploner ${ }^{4}$ und Rudolf Egger ${ }^{5}$ im Bereich der Stadtmauer statt; die Arbeiten Eggers konzentrierten sich allerdings weitgehend auf die >Friedhofsbasilikar. Die gezielte Erforschung der Stadtmauer von Aguntum begann hingegen mit den Arbeiten Innozenz Ploners, der einen Turm und zwei Tordurchlässe sowie einige an die Mauer angebaute Räume freilegen konnte. In den Jahren 1931-1935 folgten unter der Leitung von Erich Swoboda längere Grabungskampagnen am Stadttor und nördlich desselben ${ }^{6}$. Ab 1950 führte Franz Miltner systematische Grabungen durch ${ }^{7}$; er konnte nahezu den gesamten Mauerverlauf südlich des Tores freilegen. Unter der Leitung von Wilhelm Alzinger (1956-1990) wurden einige an der Stadtmauer liegende Gebäude näher untersucht ${ }^{8}$ und der Torbereich wurde neuerlich freigelegt. Ab den Sechzigerjahren rückten das Atriumhaus, das $>$ Handwerkerviertel und die große öffentliche Thermenanlage in den Mittelpunkt der Feldforschungen'. Seit dem Jahr 1991 ist das Institut für Archäologien der Universität Innsbruck unter der Gesamtleitung von Elisabeth Walde mit den Forschungen betraut $^{10}$ : In den Anfangsjahren wurden vorerst baubegleitende Grabungen im Zuge der Neuplanung der Bundesstraße 100 im Bereich des Atriumhauses und teilweise direkt an der Stadtmauer durchgeführt. Dabei konnte das Marmorbecken des Atriumhauses freigelegt werden, weshalb sich die folgenden >regulären< Grabungen vor allem auf das Umfeld dieses Gebäudes konzentrierten ${ }^{11}$.

${ }^{1}$ Zusammengestellt sind die Zufallsfunde und Grabungen ab dem 16. Jh. bis 1974 in Form einer Liste bei S. Karwiese, Der Ager Aguntinus (Lienz 1975) 76 und mit der neueren Forschungsgeschichte bei Walde 2002, 169.

2 CIL III 2, 590-592 und 1049 Nr. 6528.

${ }^{3}$ A. B. Meyer - A. Unterforcher, Die Römerstadt Agunt bei Lienz in Tirol (Berlin 1908).

${ }^{4}$ Ploner 1912, wobei die Ergebnisse seiner Grabungen im Jahre 1913 aufgrund seines Todes nicht mehr publiziert werden konnten; lediglich Planzeichnungen sind von den Arbeiten in diesem Jahr bekannt.

${ }^{5}$ R. Egger, Ausgrabungen in Norikum 1912-1913, ÖJh 17, 1914, Beibl. 8-86 und R. Egger, Frühchristliche Kirchenbauten im südlichen Norikum (Wien 1916) mit älterer Lit.

${ }^{6}$ Swoboda 1935, wobei dieser Bericht die Grabungen 1931-1933 umfasst, während die Kampagnen 1934-1935 unpubliziert blieben.

${ }^{7}$ Miltner 1953; F. Miltner, Die neuen Grabungsergebnisse in Aguntum, FuF 1953, H. 3, 89-90; Miltner 1953b, 32-34 und Miltner 1955

${ }^{8}$ Dazu vor allem Alzinger 1959; W. Alzinger, Kurzbericht über die Jahre 1982 und 1983, ÖJh 55, 1984, $42-45$ und G. Luger, Der Raumkomplex >Weggrabung Nord `von Aguntum und die in diesem Bereich gefundene grobtonige Keramik (Diss. Universität Wien 1989).

${ }^{9}$ Alzinger 1959 und weitere deutlich kürzere Grabungsberichte in den Folgejahren - aufgelistet im Literaturverzeichnis bei Alzinger, 1985.

${ }^{10}$ Zuletzt Tschurtschenthaler 2002, 1071-1089 mit Verweisen auf die weiteren Berichte über die Grabungen seit 1991 und Walde 2002, 149-163 mit ausführlichem Literaturverzeichnis.

${ }^{11}$ Dazu zuletzt: M. Tschurtschenthaler, Municipium Claudium Aguntum. Hellenistisch-römischer Wohnluxus in den Alpen, in: L. DalRi - St. di Stefano (Hrsg.), Littamum. Una mansio nel Noricum. Eine Mansio in Noricum, BAR IntSer 1462 (Oxford 2005) 105-126. 


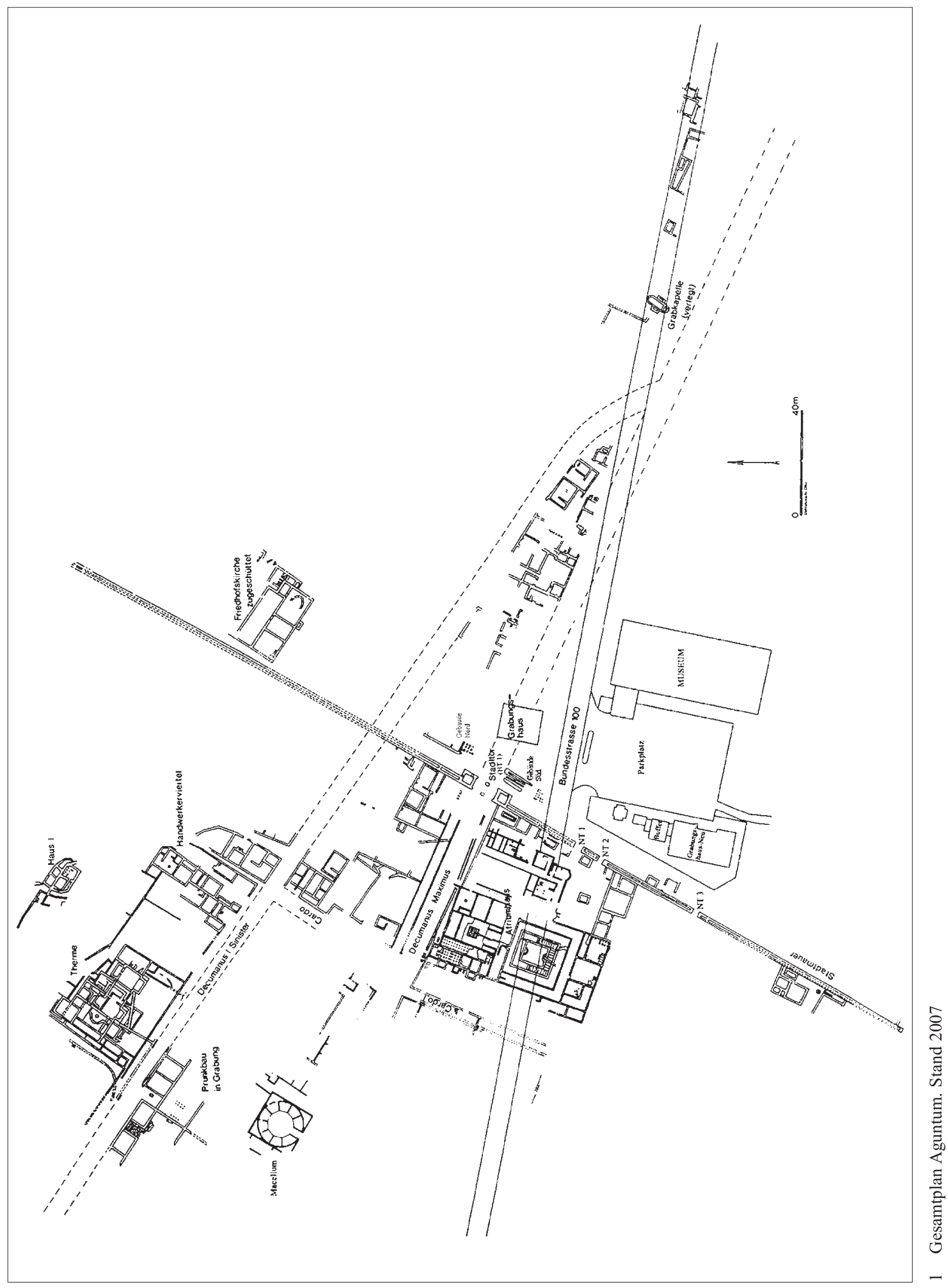


Die archäologischen Forschungen werden in Aguntum dadurch erschwert, dass das gesamte antike Stadtgebiet in nachrömischer Zeit mehrmals von Muren und Überschwemmungen heimgesucht worden war, wobei Geröllsteine und Schwemmsande bis zu einer Stärke von $6 \mathrm{~m}$ über den antiken Ruinen abgelagert wurden. Überschwemmungen mit etwas geringerem Zerstörungspotenzial fanden zuletzt $1882^{12}$ und in den Jahren 1965 und $1966^{13}$ statt. Vor allem die Zerstörungen der Sechzigerjahre des 20. Jahrhunderts bedeuteten für die Erforschung der Stadtmauer einen Rückschlag, da zum einen bereits ergrabene Gebiete meterhoch mit Schwemmsanden bedeckt wurden und nicht mehr freigelegt werden konnten und zum anderen der beschädigte, noch sichtbare antike Bestand restauriert werden musste ${ }^{14}$. Dadurch sind manche Ergebnisse der Ausgräber Erich Swoboda und Franz Miltner am Originalbestand nicht mehr ohne neuerliche Grabungen nachzuvollziehen.

\section{Die Architektur der Stadtmauer}

Die Stadtmauer besteht aus Bachstein-Schalenmauerwerk ${ }^{15}$ mit $0,85 \mathrm{~m}$ (westliche) und $0,95 \mathrm{~m}$ (östliche) breiten Futtermauern, die einen Zwischenraum von 0,65 m einschließen. Somit ergibt sich eine Gesamtbreite des Mauerwerks von 2,45 m (entspricht 8 römischen Fuß) (Abb. 2. 3). An ihren Außenseiten setzen die beiden Mauerzüge mit einem stufenförmigen, $0,70 \mathrm{~m}$ hohen Sockel ab, wobei dieser durchschnittlich $0,15 \mathrm{~m}$ über die Mauerbreite des sonstigen Oberbaus vorspringt. Das aus großen Geröllsteinen bestehende Fundament, das beiden Futtermauern gemeinsam ist, ist weitere $0,35 \mathrm{~m}$ über die Sockelkante vorgezogen (Abb. 3). Der Raum zwischen den beiden Futtermauern, die an ihren Innenseiten flüchtig gearbeitet sind, ist zum größten Teil mit Bachsteinen, Sand und Erde ausgefülltt ${ }^{16}$. Zwischen den beiden Futtermauern sind in regelmäßigen Abständen von 50 römischen $\mathrm{Fuß} \mathrm{(=14,8} \mathrm{m)} \mathrm{Quermauern} \mathrm{eingezogen}{ }^{17}$ (Abb. 2); diese konnten bei den Grabungen meist in gleicher Erhaltungshöhe wie die Futtermauern festgestellt werden. Die Quermauern dürften einen Beitrag zur Festigkeit und Haltbarkeit des Mauerwerks geleistet haben.

Der unterschiedliche Erhaltungszustand der Mauerzüge nördlich und südlich der großen Toranlage bestimmt den unterschiedlichen Kenntnisstand bezüglich der beiden $>$ Teile $<$ der Stadtmauer. Der Verlauf des Mauerzuges nach Norden wurde von Erich Swoboda ${ }^{18}$ mit drei Sondagen überprüft. Dabei konnten die beiden Futtermauern noch $166 \mathrm{~m}$ nördlich des Nordturmes festgestellt werden: Sie nehmen in ihrer erhaltenen Höhe zwischen Meter 166 und 170 stark ab, nördlich davon konnten nur noch Geröll und Murenschotter angetroffen werden. Den südlichen Verlauf der Stadtmauer konnte Swoboda bis etwa $20 \mathrm{~m}$ südlich des

${ }^{12}$ Dazu J. Althaler - M. Pizzinini - H. Waschgler, Die Hochwasserkatastrophe im 19. Jh., OTirHbl 50, 9/10, 1982, 1-16.

13 Dazu M. Pizzinini, Osttirol - eine Bezirkskunde (Innsbruck 1971) und H. Waschgler, Klima, in: G. Großlechner (Hrsg.), Bezirkskunde Osttirol (Innsbruck 1988) 16-17.

14 So schreibt W. Alzinger über die Aufräumarbeiten im Jahr 1966, dass ein Großteil des Grabungsgebiets über $1 \mathrm{~m}$ hoch von Murenschotter überdeckt war und andere Teile stark unterspült wurden (W. Alzinger in einem Brief an das ÖAI vom 28. 9. 1966, heute im Dokumentationsarchiv des ÖAI).

15 Die Technik der Schalenmauer, die bereits von Vitr. 5, 1-8 und Plin. nat. 36, 51, 172 beschrieben wird, ist in der römischen Wehrarchitektur beliebt. Insbesondere tritt sie bei Städten ab augusteischer Zeit auf, aber auch im militärischen Bereich findet diese Mauertechnik weite Verbreitung.

16 Swoboda 1935, 17-19. Die Auffüllung vieler bekannter Futtermauern im Römischen Reich (etwa jener in Köln, Avenches, Xanten, Augsburg und vieler Städte des nördlichen Italiens sowie der Hispania - zuletzt etwa: S. Ortisi, Vallum cum turribus. Zur Westumwehrung der rätischen Provinzhauptstadt Aelia Augusta/Augsburg, in: Wamser 2002, $145-156$ und Ciurletti 2002) besteht aus einem Caementitium-Gusskern. Eine Auffüllung mit Erde, Sand und Bachsteinen ist bisher singulär, lediglich das Legionslager von Windisch-Vindonissa kommt dem nahe, da dort Bauschutt und Erde verwendet wurden, um den Raum zwischen den Mauerschalen zu füllen (T. Bechert, Römische Lagertore und ihre Bauinschriften, BJb 171, 1971, 210).

17 Derartige Quermauern werden nur sehr selten verwendet, da sonst meist ein Caementitium-Kern den Zwischenraum füllt, der keine zusätzlichen Stützen benötigt, s. R. M. Butler, The construction of Urban Defences, in: Maloney - Hobley 1983, $125-129$. Die einzige bekannte Stadtmauer, die mit Sicherheit Quermauern aufweist, ist Tolosa (Toulouse): D. Cazes, La ville dans ses murs. Paladia Tolosa. Toulouse Romain (Toulouse 1989) 61-67. Vitr. 5, 3 beschreibt Querverstrebungen mit Olivenholz, die bautechnisch der Aguntiner Anlage nahe kommen, wobei in Aguntum allerdings steinerne Quermauern eingezogen wurden.

18 Swoboda 1935, 22-24. 


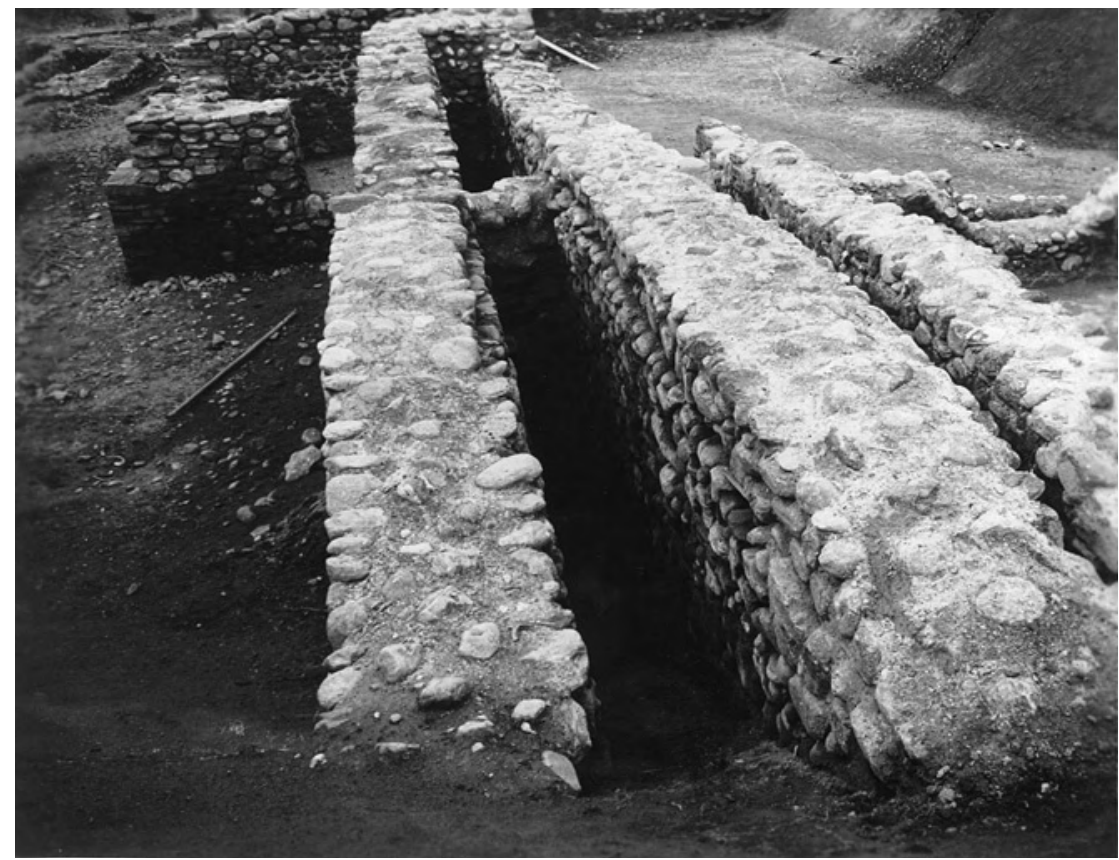

2 Ansicht des nördlichen Stadtmauerabschnitts von Norden, kurz nach dessen Freilegung; im Hintergrund der Nordturm der Toranlage

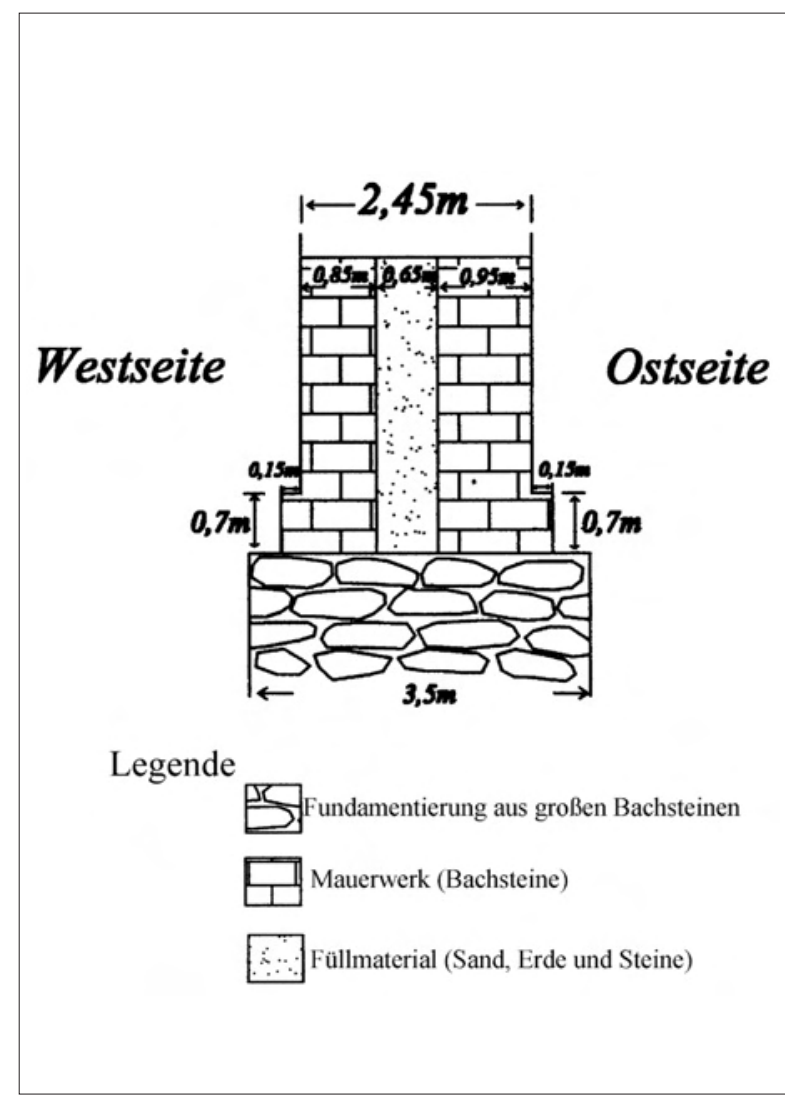

3 Schematische Darstellung des Aufbaus der Stadtmauer

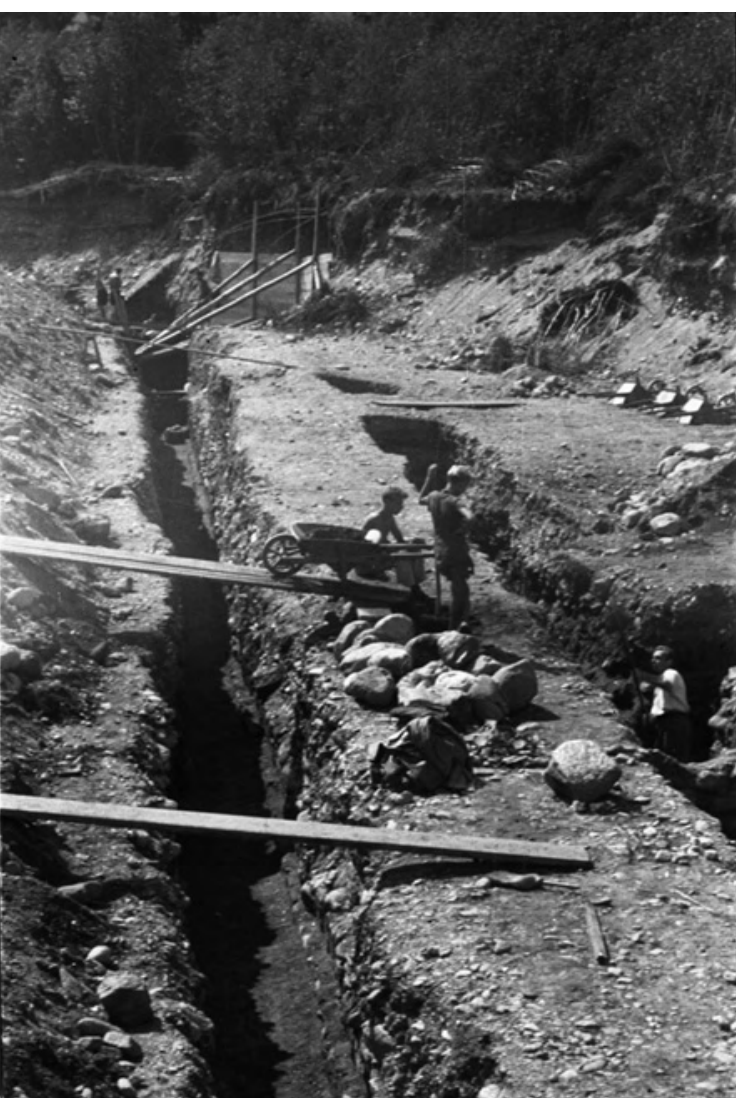

4 Südlicher Teil der Stadtmauer während der Freilegung durch F. Miltner im Jahr 1952 (Blick von Norden) 
Südturmes freilegen, wobei weiter im Süden zwei Suchgräben gezogen wurden ${ }^{19}$. Franz Miltner ${ }^{20}$ gelang es, die Mauer südlich des Tores schließlich auf einer Strecke von $177,7 \mathrm{~m}$ vor allem ostseitig durchlaufend freizulegen (Abb. 4).

\section{Die Tore der Stadtmauer}

\subsection{Die Nebentore}

Südlich der großen Toranlage wurden drei Nebentore festgestellt (Abb. 5), von denen zwei schon Innozenz Ploner bekannt waren ${ }^{21}$. Nebentor (NT) 2 mit einer durchschnittlichen Breite von 2,1 m besitzt keine rechtwinklig gelegten und auch nicht genau parallele Wangen, was Franz Miltner dazu veranlasste, hierin einen späteren Durchbruch in der Mauer zu sehen. Diese Annahme wird dadurch bestärkt, dass die beiden Züge der Stadtmauer unter dem Durchgang noch bis auf die Höhe der Sockel der Futtermauern durchlaufen und die unregelmäßigen Torwangen aufgrund des hier verwendeten kleineren Steinmaterials als späteres Flickwerk anzusehen sind. Nebentor 3 (NT 3) ist 2,40 m breit und exakt rechtwinklig durch die Mauer gelegt. Allerdings war NT 3 ebenfalls nicht im ursprünglichen Bauplan vorgesehen, da auch hier die beiden Mauerzüge in Sockelhöhe durchlaufen. Anders als bei NT 2 sind die Wangen dieses Tores im Zwischenraum der beiden Mauerzüge vom Stadtmauerfundament her aufgemauert, wobei das gleiche Steinmaterial wie für die Stadtmauer verwendet wurde.

NT 1 wurde erst im Zuge der Grabungen Franz Miltners entdeckt. Es befand sich unmittelbar südlich des ursprünglichen Dammes der Bundesstraße und weist eine Breite von 3,55 m auf. Der wesentliche Unterschied zu den beiden anderen Nebentoren ist, dass die beiden Bahnen der Stadtmauer nicht unter dem Torbereich durchlaufen, sondern in einem etwa $0,25 \mathrm{~m}$ vorspringenden Sockel an den beiden Torwangen zusammengefasst sind. Auf diesem Sockel sind die Torwangen in >schöner Glattmauerung` erbaut - sie waren bei Freilegung noch über $2 \mathrm{~m}$ hoch erhalten -, wobei in den beiden untersten Lagen Bachsteine, darüber aber plattenförmige Schiefersteine verwendet worden waren. Die aufwendige Mauertechnik und das Fehlen der Mauerzüge unter der Fahrbahn sind der Beweis, dass dieses Nebentor von Anfang an im Bauplan der Stadtmauer vorgesehen war.

An der Ostseite der Ummauerung fanden sich an mehreren Stellen plattenförmige Steinblöcke, welche sich nach Franz Miltner wohl als Pflasterung entlang der Mauer ergänzen lassen, besonders da die Steinlage auch innerhalb der Durchgänge der Nebentore vereinzelt aufgedeckt werden konnte. Es wird somit längs der Stadtmauer ein gepflasterter Gehweg anzunehmen sein.

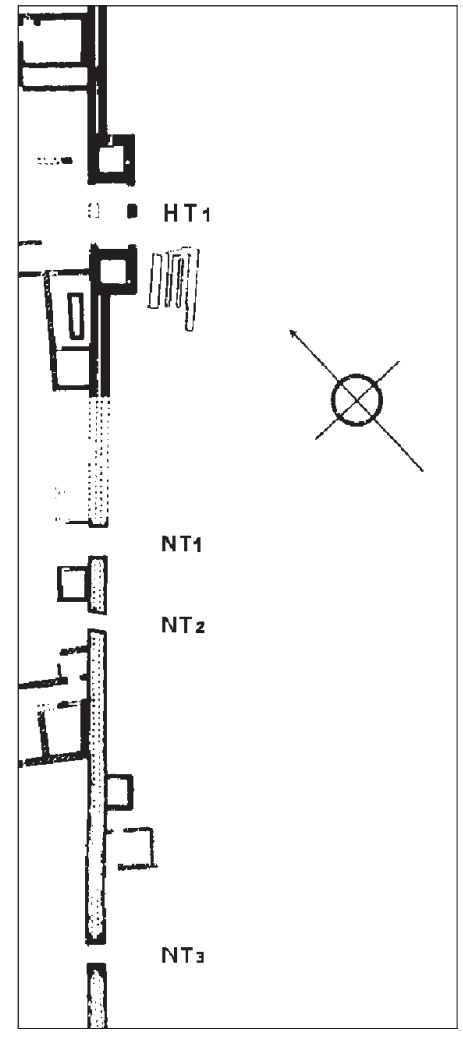

5 Planzeichnung der von F. Miltner beschriebenen Haupt- und Nebentore

Franz Miltner konnte auch das vorläufige Südende der Stadtmauer feststellen ${ }^{22}$. An diesem - ca. $185 \mathrm{~m}$ vom Haupttor entfernt - ist die Quermauer, welche die beiden Futtermauern verbindet, in üblicher Technik mit großen und teilweise bearbeiteten Bachsteinen errichtet. Dem Ausgräber schien hier ein ursprüngliches Tor wahrscheinlich, weshalb noch etwa 5,5 m über die Abschlusswange der Stadtmauer hinaus nach Süden gegraben wurde. Obwohl man sich auf dem Niveau der Sohle der Fundamentgrube befand, konnte keine

\footnotetext{
19 Swoboda $1935,24-25$.

${ }^{20}$ Miltner 1953, 97-103.

21 Ploner 1912, und zwar NT 2 (nach Graf Toggenburg benannt) und NT 3 (Tor Baron Kathrein).

22 Miltner 1953, 105-108.
} 
Spur einer Gegenwange entdeckt werden. Wegen der besonders schwierigen Verhältnisse in diesem Areal die Fundamentsohle lag mehr als $7 \mathrm{~m}$ unter dem rezenten Niveau - sowie dem recht nahen Damm des Debantbaches ${ }^{23}$ konnten keine weiteren Untersuchungen durchgeführt werden.

\subsection{Das >Haupttor<}

Dort, wo sich heute die größte bisher festgestellte Toranlage der Aguntiner Stadtmauer befindet, war im ursprünglichen Bauplan der Mauer ein wesentlich kleineres Tor vorgesehen, dessen Fundamente unterhalb des großen Tores bereits von Erich Swoboda ${ }^{24}$ (Abb. 6) und später von Wilhelm Alzinger (Abb. 7) festgestellt werden konnten. Dieses Tor besa 3 nur eine etwa 3,5 m breite Durchfahrt, wobei zuletzt Alzinger ${ }^{25}$ annahm, dass der Umbau zur großen Toranlage bereits wenige Jahre nach Fertigstellung der ersten Bauphase erfolgt war.

Die große Toranlage besteht aus ei-

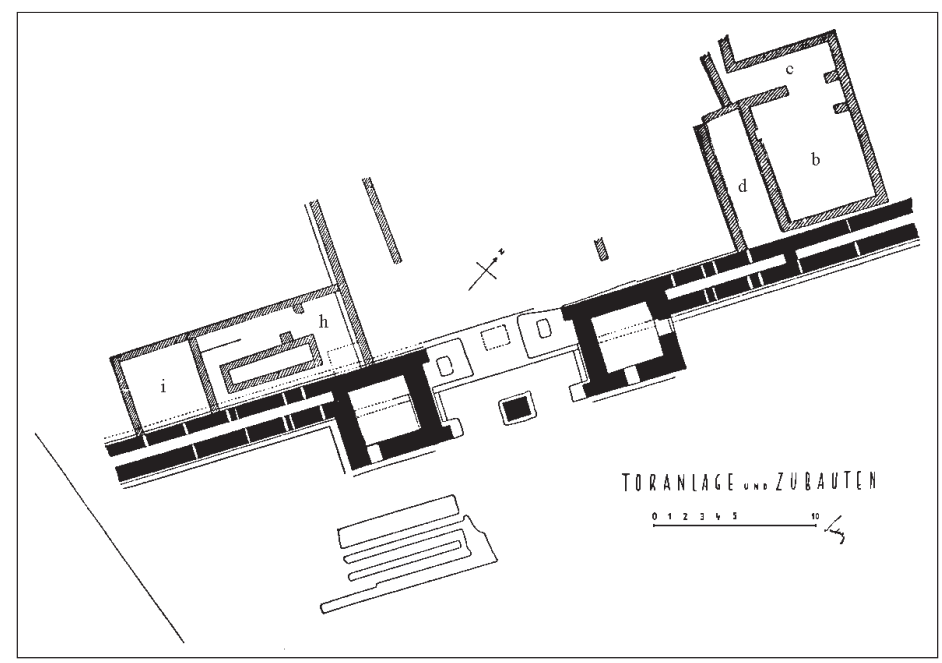

6 Planzeichnung der Toranlage nach E. Swoboda mit den Fundamenten der älteren Torphase

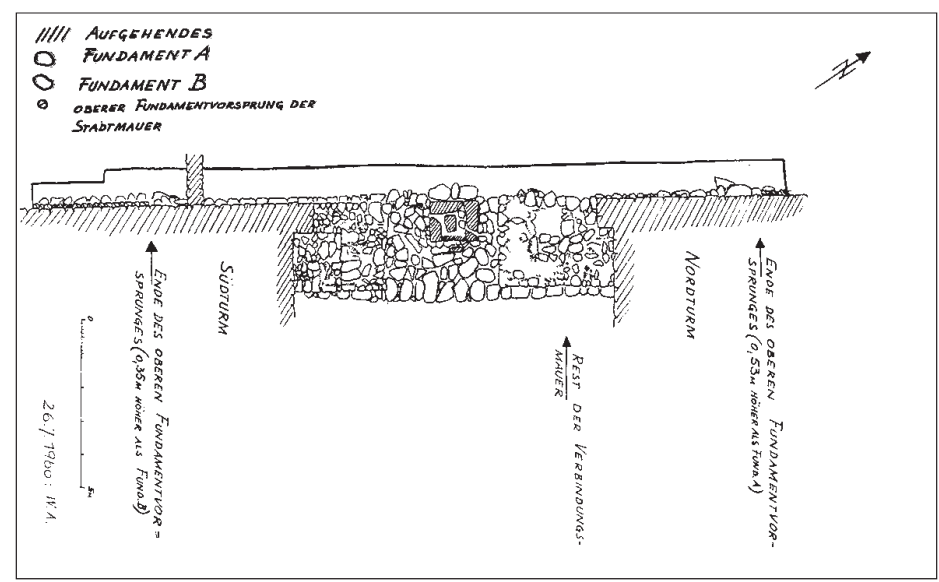

7 Fundamente der älteren Torphase, Planzeichnung W. Alzingers ner doppelten Durchfahrt, flankiert von zwei fast quadratischen Tortürmen ${ }^{26}$. Die Türme weisen eine Seitenlänge von $6 \mathrm{~m}$ auf und waren bei ihrer Freilegung noch etwa 2,5 $\mathrm{m}$ hoch erhalten (Abb. 8). Die Mauern sind 1,2 $\mathrm{m}$ breit und entsprechen in Technik und Material der Stadtmauer. Eine Ausnahme bilden die Ostmauern der Türme: Anstelle der Bachsteine sind in ihrer unteren Hälfte große, ca. $1 \mathrm{~m}$ lange und $0,25 \mathrm{~m}$ hohe, z. T. bearbeitete Steinplatten (Schiefer, bearbeitete Bachsteine) versetzt. Nach oben hin werden diese von rechtwinklig zugerichteten und an der Außenseite geglätteten Schieferplatten (in der Regel $0,6 \mathrm{~m}$ lang und $0,1 \mathrm{~m}$ hoch) abgelöst. An beiden Ostmauern wurde ebenso eine je $0,7 \mathrm{~m}$ breite und $0,4 \mathrm{~m}$ hohe Öffnung erkannt. Die West- und Ostwände der Turmmauern sind jeweils $0,5 \mathrm{~m}$ weit in die Durchfahrt vorgezogen und bilden hier einen $0,87 \mathrm{~m}$ breiten Pfeiler. In der Mitte der ca. 9,5 m breiten Durchfahrt konnte ein $1,5 \mathrm{~m}$ langer und $1,2 \mathrm{~m}$ breiter Mittelpfeiler aus Schieferplatten freigelegt werden. Analog dazu wird von Erich Swoboda auch in der Visierlinie der westlichen Turmpfeiler ein Mittelpfeiler mit gleichen Maßen rekonstruiert, wenngleich dieser auch nur noch anhand einiger weniger Schieferplatten festgestellt werden konnte ${ }^{27}$. Damit besteht die zweite und abschließende Bau-

\footnotetext{
${ }^{23}$ Miltner 1953b, 32-34.

${ }^{24}$ Swoboda 1935, bes. 44-45.

${ }^{25}$ Alzinger 1960, 31.

${ }^{26}$ Swoboda 1935, 33-45.

27 Vgl. Swoboda 1935, 41.
} 
phase des großen Tores aus einer, angesichts der festgestellten Pfeilerreste, wohl überwölbten, von zwei Türmen flankierten, doppelten Durchfahrt (je 3,55 m breit).

\subsubsection{Die Turmzugänge}

Erich Swoboda ${ }^{28}$ stellte in der Nordwange des Nordturmes eine etwa $1 \mathrm{~m}$ breite Türöffnung fest, die Franz Miltner ${ }^{29}$ als Indiz für eine sekundäre Verwendung des Turmgemachs als Wohnraum interpretierte (Abb. 9). Da der ursprüngliche Befund am großen Tor infolge von Restaurierungen (im Jahr 1947 wurde mit den Arbeiten begonnen, allerdings $» \mathrm{mehr}$ im Sinne einer Renovierung als einer Konservierung des Erhaltenen $\aleph^{30}$ ) schon zur Zeit Miltners verwischt war, musste dieser sich auf die Angaben Swobodas und dessen Photos des Tores während der Freilegung verlassen. Miltner postulierte einen Zugang zu den Türmen jeweils von Westen, wobei dies für den Südturm schon aus den Beobachtungen Erich Swobodas hervorging ${ }^{31}$. Swoboda hatte zwar eine ehemalige Verbindung von Raum h zum Turm hin erkannt, nahm hier aber eine späte Nutzung des Turmes als Wohngemach $\mathrm{an}^{32}$. Diese Interpretation ist wohl dadurch beeinflusst, dass er die Stadt im Osten der Stadtmauer lokalisierte und ein Zugang zum Turm von außerhalb der Stadt für ihn erst im Zuge einer Nachnutzung denkbar war.

Für den Nordturm konstatierte Franz Miltner aufgrund von Beobachtungen an Swobodas Grabungsphotos eine analoge Tür in der Westwand, wobei es sich hier um eine später zugemauerte Öffnung handeln würde, die anhand der Verfärbungen

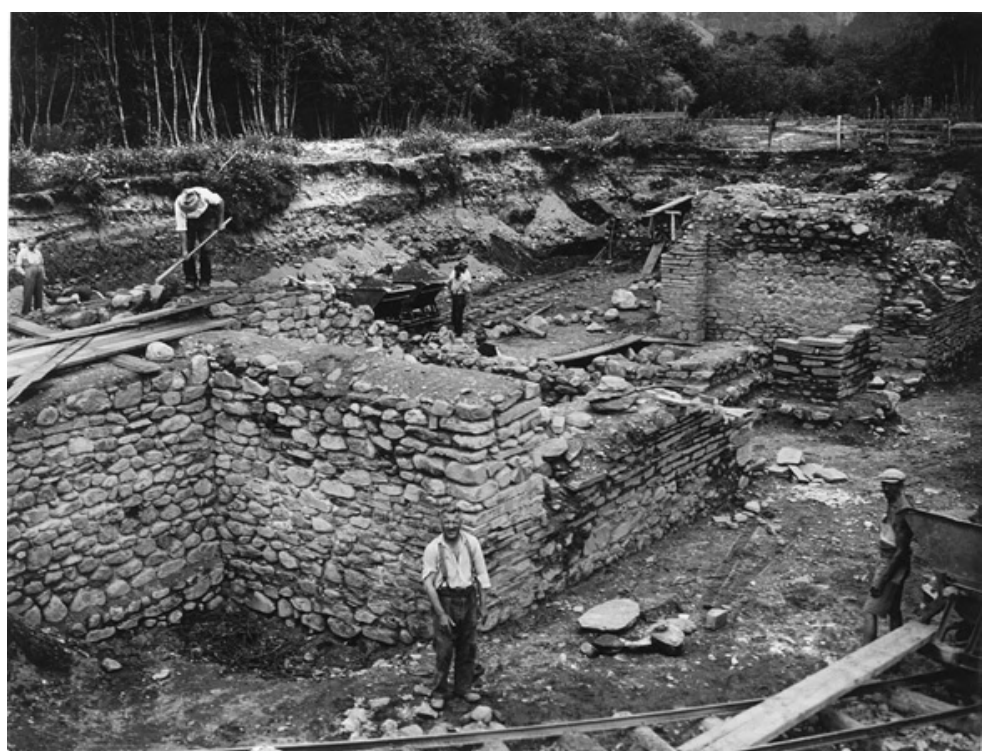

8 Die Toranlage während der Freilegung durch E. Swoboda (Blick von Südosten)

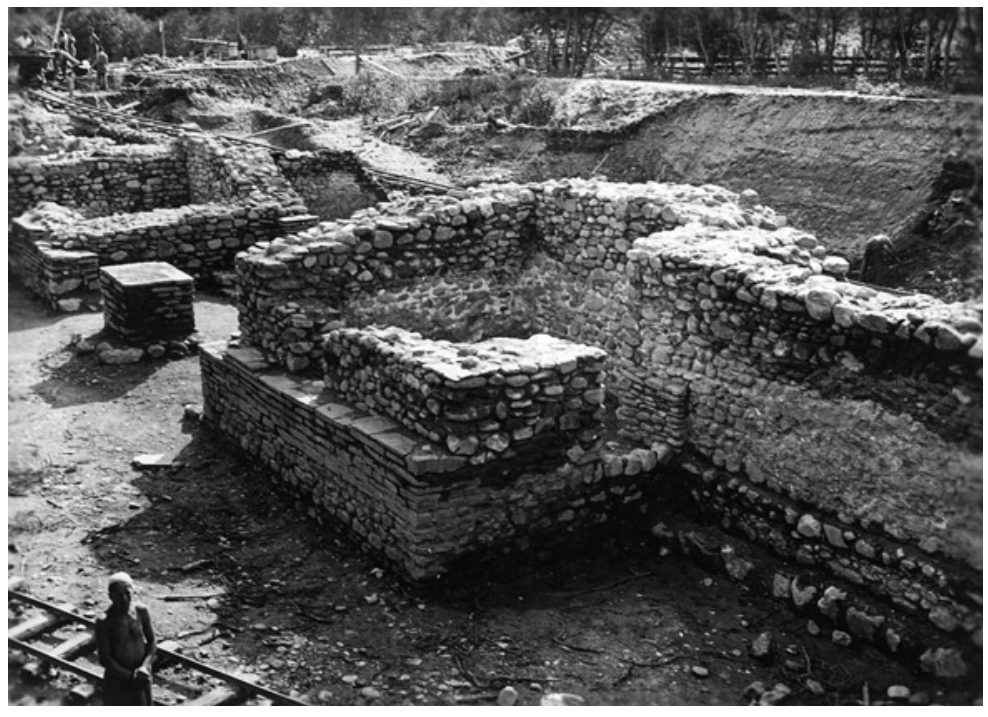

9 Ansicht des Tores von Nordosten während (bzw. nach) Arbeiten E. Swobodas im Mauerwerk sowie den Mauerfugen zu erkennen sei. Da eine Überprüfung dieser Interpretation am Originalbefund schon Miltner nicht mehr möglich war, bleibt der Zugang zum Nordturm von Westen her allerdings ohne Beleg. Die Türschwelle des $>$ Außenzugangs $<$ der Nordwange des Nordturmes liegt auf etwas höherem Niveau als der Fundamentvor-

\footnotetext{
${ }^{28}$ Swoboda $1935,37-38$.

${ }^{29}$ Miltner 1953, 148-156.

${ }^{30}$ So Miltner 1953, 7.

${ }^{31}$ Swoboda 1935, 34-36.

${ }^{32}$ Swoboda 1935, 65.
} 
sprung der anschließenden Stadtmauer, was die Interpretation als eine später eingebaute Türöffnung stützt. Allerdings spricht die sorgfältig gemauerte Westfront des Zugangs eher für einen ursprünglich geplanten Eingang (s. Abb. 9). Die unvereinbaren Niveaus der Türschwelle und des Bodens innerhalb des Turmes mit dem durch den Fundamentvorsprung der Stadtmauer markierten Außenniveau können ganz einfach mit einer Treppe überbrückt werden und sind somit kaum ein gewichtiger Grund, den Zugang als sekundär anzusehen.

\section{Das Datierungsproblem der Stadtmauer von Aguntum}

Insgesamt ergibt sich aus dem bisher Gesagten das Bild einer Befestigungsanlage mit mehreren, nacheinander entstandenen Tordurchlässen ${ }^{33}$. Allein aufgrund dieser Tatsache scheint es wahrscheinlich, dass die Stadtmauer während einer länger andauernden Friedenszeit bestand, denn sonst hätte man wohl kaum nachträgliche Nebentore angelegt, die eine Verteidigung der Stadt erheblich erschwerten. Ebenso scheint der Umbau des großen Tores und seiner ursprünglich einbahnigen Durchfahrt in eine zweibahnige in Bezug auf die Verteidigung der Stadt nicht besonders schlüssig ${ }^{34}$. Besonders dann nicht, wenn die Türme einmal von Westen (Südturm) und einmal von Osten (Nordturm) zugänglich waren, was bei derzeitigem Forschungsstand anzunehmen ist. Als Grund für die Verbreiterung des Tores dürfte unter diesen Umständen eher ein größeres Verkehrsaufkommen anzunehmen sein.

Mit der Entdeckung der Stadtmauer durch Innozenz Ploner ${ }^{35}$ ergab sich die Frage, auf welcher Seite der Stadtmauer die antike Stadt nun zu suchen sei. Erich Swoboda ging nach Abschluss seiner Grabungen davon aus, dass die Stadt im Osten des bekannten Mauerzuges liegen müsse ${ }^{36}$. Mit den Arbeiten von Franz Miltner wurde schließlich klar, dass sich die eigentliche Stadt im Westen der Stadtmauer befunden haben musste, was Miltner anhand des Grabungsbefundes auch eingehend darlegte ${ }^{37}$. Lediglich Alfons Wotschitzky ${ }^{38}$ wi- $^{\text {- }}$ dersprach dieser Deutung und lokalisierte Aguntum wiederum östlich der Ummauerung, was auch Wilhelm Alzinger kurz in Erwägung zog, um die Mauer - ebenso wie Wotschitzky - als Murenschutzmauer zu interpretieren $^{39}$. Nach den heute bekannten baulichen Resten ${ }^{40}$ (s. Abb. 1) ist mit Sicherheit davon auszugehen, dass sich das Zentrum des antiken Municipium Claudium Aguntum westlich des bekannten Stadtmauerabschnitts befand.

\footnotetext{
${ }^{33}$ Einfache Nebentore, wie sie hier in Aguntum vorkommen, sind bei römischen Wehrmauern nicht der Regelfall. Es sind in diesem Zusammenhang vor allem Nebentore in Form von in die Mauer eingelassenen Türmen bekannt (etwa in Turin, Avenches, Köln, Xanten und Merida - dazu Ch. Weiss, Die frühkaiserzeitlichen Stadtbefestigungen auf der iberischen Halbinsel: Fortifikatorische Funktion und Bedeutung für das urbane Erscheinungsbild [Dissertation Universität Köln 1997] 157-158). Einfache Durchgänge, sog. Poternen, wurden von Ch. Weiss in Zaragossa, Mérida und Baelo (Weiss a. O. 158-159) sowie in Frejus (L. Rivet - D. Brentchaloff - S. Roucole - S. Saulnier, Atlas topographique des villes de Gaulle Mérodionale II. Frejus, RANarb Suppl. 32 [Aix-en-Provence 2000] 352-356) festgestellt. Die weitgehende Unkenntnis solcher Maueröffnungen dürfte aber wohl eher auf eine Forschungslücke als auf eine andere Begründung zurückgehen, da Poternen, insbesondere wenn sie später eingebaut wurden, nur als solche zu erkennen sind, wenn von der Stadtmauer mehr erhalten ist als das Fundament und große Strecken der Mauer erforscht sind.

${ }^{34}$ Swoboda 1935, 45-50 sieht im Umbau des Tores eine fortifikatorische Maßnahme.

35 Ploner 1912.

36 Swoboda 1935; seine Grabungen östlich der Stadtmauer deckten Besiedlungsspuren auf, während schon R. Egger (Anm. 1:1914) 8-86 westlich des Stadtmauerzuges zwei kaiserzeitliche Gräber feststellen konnte. Diese Indizien führten zu dem logischen Schluss, dass die antike Stadt im Osten der Stadtmauer liege, wenn auch die von Egger (Anm. 1:1916) freigelegte Friedhofsbasilika der Tradition entsprechend außerhalb der Stadt hätte liegen müssen.

${ }^{37}$ Miltner 1953, 141-156.

${ }_{38}$ A. Wotschitzky, Zum Tor-Problem von Agunt, AnzAW 5, 1952, 119-123.

39 W. Alzinger, Aguntum. Zusammenfassung und Kurzbericht für die Jahre 1978-1981, ÖJh 53, 1981/1982, 49. Allerdings wird in dem 1985 von Alzinger erstellten Führer durch Aguntum und Lavant die Lage der Stadt wieder westlich der Mauer angenommen: Alzinger 1985, 37-38.

${ }^{40}$ Dazu Walde 2002, 149-163; E. Walde, Das Municipium Claudium Aguntum, in: Spurensuche ${ }^{3}$. I. Vom Schnabelmenschen zur Zwerglstadt. Katalog zur Ausstellung des Museums der Stadt Lienz Schloss Bruck (Innsbruck 2005) 63-69 und Tschurtschenthaler 2002, 1071 - westlich des Atriumhauses und südlich der großen Therme konnten in einem Suchschnitt zahlreiche innerstädtische Gebäude festgestellt werden, von denen das Macellum in den Jahren 2006 und 2007 vollständig ausgegraben werden konnte.
} 
Erich Swoboda ging bei seiner Datierung von der Lage der Stadt im Osten aus und kam über den Vergleich der Toranlage mit anderen Toranlagen kaiserzeitlicher Städte zu dem Ergebnis, dass die Mauer um die Mitte des 2. Jahrhunderts $n$. Chr. errichtet ${ }^{41}$ und der Umbau der großen Toranlage Ende des 2. Jahrhunderts bzw. Anfang des 3. Jahrhunderts n. Chr. in Angriff genommen worden war. Als Anlass für die Errichtung der Stadtmauer führte er die Markomannenkriege sowie den Alamannenfeldzug Caracallas an ${ }^{42}$. Allerdings weicht diese 1935 publizierte Datierung von den Angaben einer nur ein Jahr älteren Publikation ab, in der Swoboda von zwei zeitlich getrennten Bauperioden der Stadtmauer in den beiden ersten Jahrhunderten nach Christus spricht ${ }^{43}$. Franz Miltner beschäftigte sich weniger eingehend mit der Frage der Datierung als mit der Beweisführung für die Lage der Stadt ${ }^{44}$ und übernahm wohl Swobodas Begründungen bezüglich der Notwendigkeit einer Verteidigungsanlage in der zweiten Hälfte des 2. Jahrhunderts n. Chr., wenn er den Bau der Stadtmauer in die Zeit der Markomannenkriege setzt ${ }^{45}$. Miltner kam aber, insbesondere durch die Ergebnisse der Grabungen des Jahres $1953^{46}$, zu dem Schluss, dass die Stadtmauer »früher als bisher angenommen $\aleph^{47}$ datiert werden müsse. Eingehend mit der Frage nach der Funktion und Datierung der Stadtmauer beschäftigte sich Wilhelm Alzinger ${ }^{48}$, der in der Aguntiner Mauer einen Repräsentationsbau sah, der anlässlich der für das 2. Jahrhundert angenommenen ${ }^{49}$, aber nie bewiesenen Erhebung Aguntums zur Colonia errichtet worden war. Zuletzt war es Verena Gassner, die sich mit Datierung und Funktion der Stadtmauer von Aguntum auseinandersetzte ${ }^{50}$. Anhand typologischer Vergleiche des Tores in Aguntum mit den Torbauten anderer römischer Städte stellt sie fest, dass vor allem im 1. und ab dem Ende des 2. Jahrhunderts n. Chr. der Aguntiner Mauer ähnliche Stadtmaueranlagen bekannt sind. Aufgrund der Auswertung des Grabungsbefundes bis 1985 gelangt Gassner zur Ansicht, dass es sich in Aguntum um eine Stadtbefestigung handeln muss, die gegen Ende des 2. Jahrhunderts n. Chr. als Schutz gegen die Alamannen-Einfälle erbaut wurde.

Alle bisherigen Ansätze zur Datierung der Stadtmauer sind primär von dem Befund an der Stadtmauer selbst ausgegangen, wobei im Wesentlichen Vergleiche mit anderen Toranlagen herangezogen wurden. Der einfachste Weg zu einer Datierung der Mauer zu gelangen, wären Funde im Verfüllungsmaterial zwischen den beiden Futtermauern. Und tatsächlich ist eine Münze des Kaisers Hadrian, die schon unter Erich Swoboda entdeckt wurde ${ }^{51}$, immer wieder ein Hauptargument, die Stadtmauer nach der Mitte des 2. Jahrhunderts n. Chr. anzusetzen. Doch bei einer genaueren Untersuchung der Fundlage dieser Münze stellt man zunächst bei Swoboda ${ }^{52}$ fest, dass sie sich in der Verfüllung an der Fundamentoberkante der Mauer befand, und zwar ca. $20 \mathrm{~m}$ nördlich des Nordturmes. Wie aber die Grabungen Franz Miltners ergaben ${ }^{53}$, ist die Stadtmauer ab etwa 19 m nördlich des Nordturmes durch einen Murenarm (mit Streichrichtung fast Nord-Süd) völlig zerstört. Somit kann diese Münze keinesfalls zur Datierung der Stadtmauer heran-

\footnotetext{
41 Swoboda $1935,42-45$.

42 Swoboda $1935,49$.

43 E. Swoboda, Die Ausgrabungen in Aguntum bei Lienz in Osttirol, FuF 1934, H. 2, 17-18. Die hier publizierte Meinung zur Datierung findet ihre Bestätigung in einem Brief von E. Swoboda vom 3. 9. 1932, in dem er wage von bestimmten Momenten spricht, die als Hinweise auf eine schon in das 1. Jh. n. zurückreichende Bauperiode zu verstehen wären (dieser Brief befindet sich im Dokumentationsarchiv des ÖAI in Wien, Akte 54/1932). Damit ist auch klar, dass Swoboda zumindest von 1932-1934 der Ansicht war, die Stadtmauer hätte eine in das 1. Jh. n. Chr. zurückreichende Bauphase. Umso erstaunlicher ist es, dass bei seiner Publikation 1935 dieser ältere Datierungsansatz völlig unerwähnt bleibt.

44 Miltner 1953.

${ }^{45}$ F. Miltner, Die neuen Grabungsergebnisse in Aguntum, FuF 1953, H. 3, 89.

46 Miltner 1955.

47 Miltner 1953b, 32-34.

48 Alzinger 1960.

49 Gegen die Erhebung des Municipium Aguntum in den Status einer Colonia in hadrianischer Zeit spricht das Fehlen jeglicher Belege. Dazu M. Zahrnt, Vermeintliche Kolonien des Kaisers Hadrian, ZPE 71, 1988, 233-234 - hier wird auch vermerkt, dass die Stadt auch nach Ende des 2. Jhs. n. Chr. noch inschriftlich als Municipium erwähnt wird, ohne irgendwelche Zusätze, die auf eine Kolonieerhebung deuten würden.

50 V. Gassner, Zur Funktion und Datierung der Stadtmauer von Aguntum, RÖ13/14, 1985/1986, 77-100.

51 Swoboda 1935, 22.

52 Swoboda $1935,21-22$.

53 Miltner 1953, 97.
} 


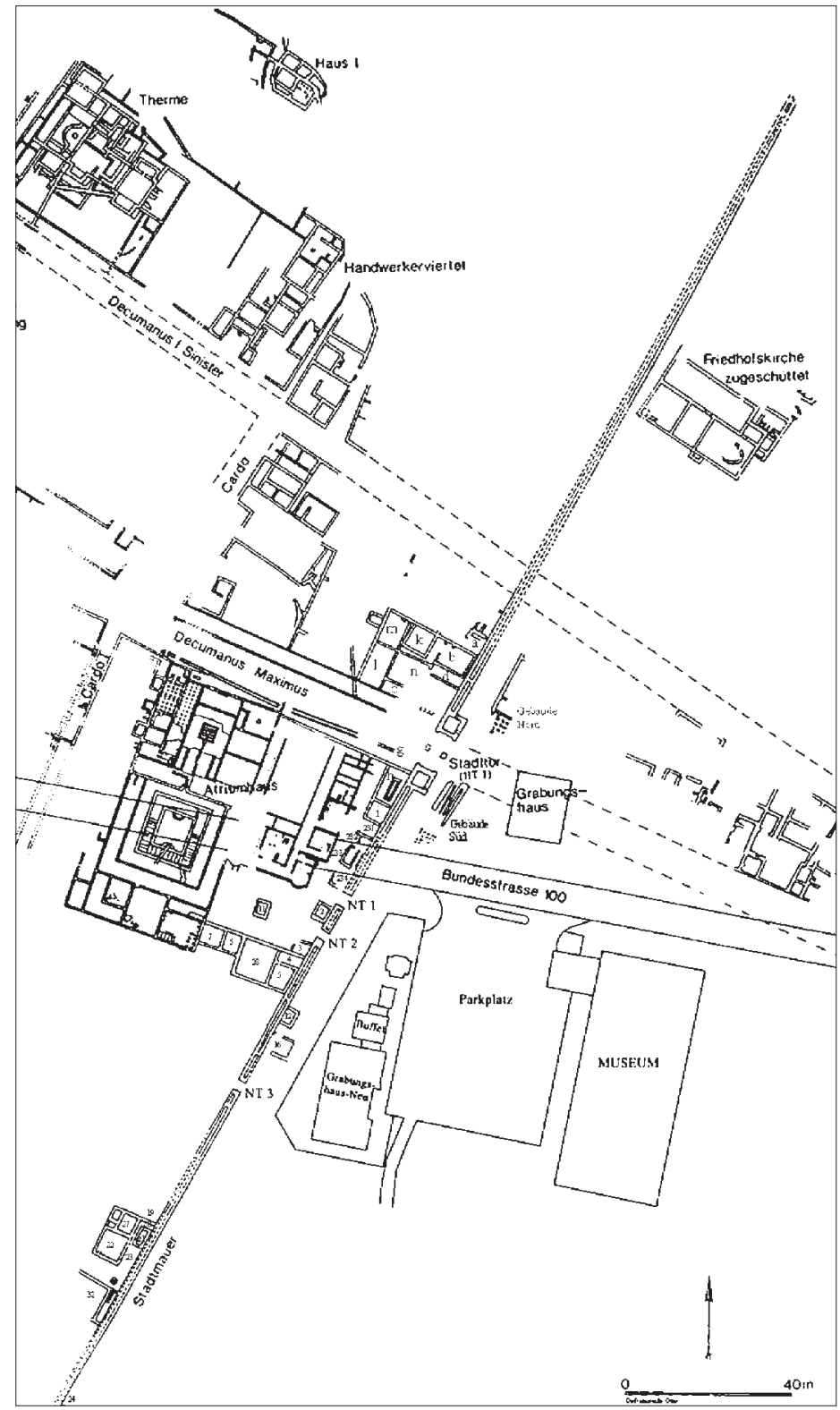

10 Ausschnitt aus dem Gesamtplan mit Raumbezeichnungen der an die Stadtmauer angebauten Räumlichkeiten gezogen werden, da sie wahrscheinlich erst mit der Murenzerstörung in nachantiker Zeit an ihren späteren Fundort gelangte. Erich Swoboda berichtet auch von weiterem Fundmaterial, das sich an der ersten Quermauer innerhalb der Stadtmauer nördlich des Nordturmes fand $^{54}$. Interessanterweise liegen die Funde nördlich der Quermauer neuerlich auf der Fundamentoberkante der Stadtmauer, während die Funde südlich der Quermauer schon »in der obersten Schichte« entdeckt wurden. Diese Fundposition legt nahe, dass auch diese Funde von Mure und Überschwemmung herangetragen wurden. Die Funde selbst wurden von Wilhelm Alzinger in seiner Materialpublikation ${ }^{55}$ nicht berücksichtigt, womit die Angaben Swobodas für eine allfällige Datierung ausreichen müssen. Da dieser aber keine genauen Angaben zum Fundort der einzelnen Stücke macht, ist nicht klar, ob sich alle hier aufgezählten Funde bei der ersten Quermauer nördlich des Nordturmes fanden oder dem zweiten Fundort innerhalb der Stadtmauer zwischen $166 \mathrm{~m}$ und $167 \mathrm{~m}$ nördlich des Nordturmes zugehören $^{56}$. Das einzige ohne Zweifel diesem zweiten Fundort zuordenbare Stück ist eine Münze des Claudius ${ }^{57}$. Allerdings ist auch hier die Situation ähnlich wie $20 \mathrm{~m}$ nördlich des Nordturmes - der Erhaltungszustand der Mauer ist nämlich bedingt durch die Murenzerstörung sehr schlecht ${ }^{58}$. Somit bringen die nur vermeintlich in der Verfüllung der Schalenmauer liegenden Funde keine Lösung des Datierungsproblems ${ }^{59}$.

Interessanter sind hier die an die Stadtmauer anschließenden Räumlichkeiten (Abb. 10), die großteils schon in den Fünfzigerjahren erforscht wurden, wobei eine stratigraphische Zuordnung von Funden heute leider nur in den wenigsten Fällen möglich ist. Es zeigt sich allerdings aus

${ }^{54}$ Swoboda 1935, 21-22.

55 W. Alzinger, Kleinfunde von Aguntum aus den Jahren 1950 bis 1952 (Wien 1955).

${ }^{56}$ Die bei Swoboda 1935, 50-52 angeführten Funde datieren in die ersten beiden Jahrhunderte n. Chr. Da die Einschwemmung dieser Funde mit ziemlicher Sicherheit durch eine (in Nord-Süd-Richtung verlaufende) Mure anzunehmen ist, stammen sie wohl aus dem nördlichen Teil der Stadt.

57 Swoboda 1935, 24 und 50-52.

${ }^{58}$ Swoboda 1935, 24.

${ }^{59} \mathrm{Zu}$ erwähnen ist in diesem Zusammenhang auch ein »hadrianischer Börsenarmreif«, der von W. Alzinger zur hadrianischen Datierung der Stadtmauer herangezogen wurde (Alzinger 1960, 35). Da dieser aber in einer Brandschicht über dem Fundament- 
den Grabungspublikationen in Verbindung mit der Materialpublikation Wilhelm Alzingers, dass Gebäude, die eindeutig erst nach Errichtung der Stadtmauer erbaut worden sein konnten, schon im 2. Jahrhundert n. Chr. benutzt wurden ${ }^{60}$; vor allem sind hier der Baukomplex um Raum 21 und die Abfallgrube unterhalb der Räume 232-234 sowie die Räume h und i zu nennen, mit Einschränkungen auch Raum 12 und der Baukomplex um Raum b. Eine Datierung des Mauerbaus nach der Mitte des 2. Jahrhunderts n. Chr. ist somit auszuschließen. Aufgrund des verhältnismäßig hohen Anteils früher Fundstücke in den Anbauten, u. a. Amphorenmaterial mit Stempeln aus dem 1. Jahrhundert n. Chr., das zu großen Teilen Entsprechungen am Magdalensberg findet, spricht nichts gegen eine Datierung des Baubeginns der Aguntiner Mauer noch im 1. Jahrhundert n. Chr. Eindeutig zu trennen sind hier aber der eigentliche Mauerbau und der Bau des >Osttores` der Stadt, da es sich an dieser Stelle um eine nachträgliche Planänderung handelt und ursprünglich nur ein einfacher Durchlass vorhanden war. Das aus den Altgrabungen hervorgehende Bild bestätigte sich nun auch durch die Auswertung einer 1994 unmittelbar vor dem Osttor durchgeführten Grabung des Instituts für Archäologien der Universität Innsbruck.

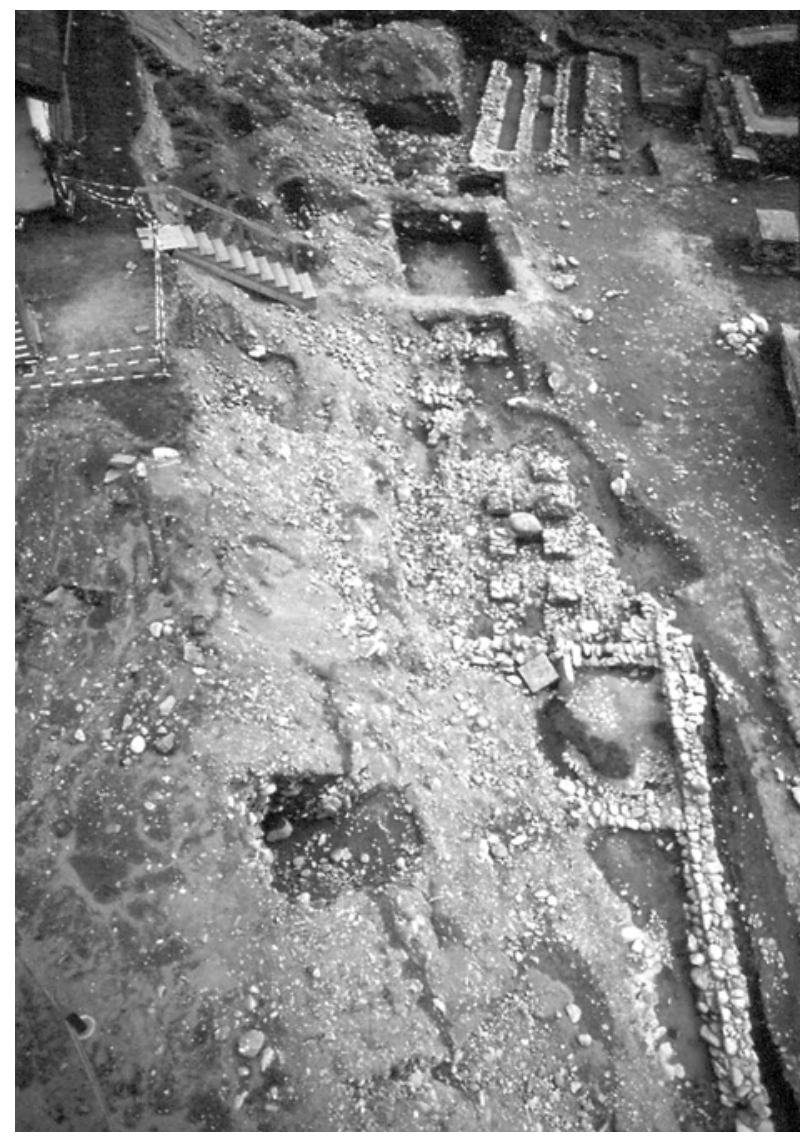

11 Gesamtansicht des Grabungsbereichs >Stribachweg 1994 (Blick von Norden)

\section{Der Befund der Grabung >Stribachweg 1994^}

\subsection{Allgemeines}

Im Jahr 1994 fand eine Ausgrabung des Instituts für Archäologien (damals: Institut für klassische und provinzialrömische Archäologie) der Universität Innsbruck auf Parzelle 40/4 der Katastralgemeinde Stribach statt, die aufgrund des an dieser Stelle geplanten Wirtschaftsweges unter dem Namen >Stribachweg 1994く geführt wurde. Dabei wurden unmittelbar vor dem Osttor der Stadtmauer zwei Gebäude freigelegt (Abb. 11). Beide Bauten waren bei den Arbeiten Erich Swobodas in den Dreißigerjahren des 20. Jahrhunderts schon teilweise berührt oder ausgegraben, sind aber bei der Überschwemmungskatastrophe der Sechzigerjahre wieder verschüttet und nicht mehr freigelegt worden. In den Plänen Swobodas wird das von ihm fast vollständig ergrabene südliche Gebäude mit »Fundamentstreifen« eingezeichnet und im Text erwähnt, während das nördliche Gebäude, von dem, wie 1994 festgestellt werden konnte, Swoboda nur einen kleinen Teil angegraben hatte, keine Erwähnung findet.

vorsprung der Stadtmauer gefunden wurde (Alzinger 1959, 127), besitzt er für eine Datierung der Erbauungszeit der Stadtmauer nur geringere Relevanz als terminus ante quem.

${ }^{60}$ Ausführlich in M. Auer, Beobachtungen zur Entstehungszeit der Stadtmauer von Aguntum. Mit einer Betrachtung der Forschungsgeschichte und der Datierungsansätze von 1912 bis 2005 (Mag. Universität Innsbruck 2006). 


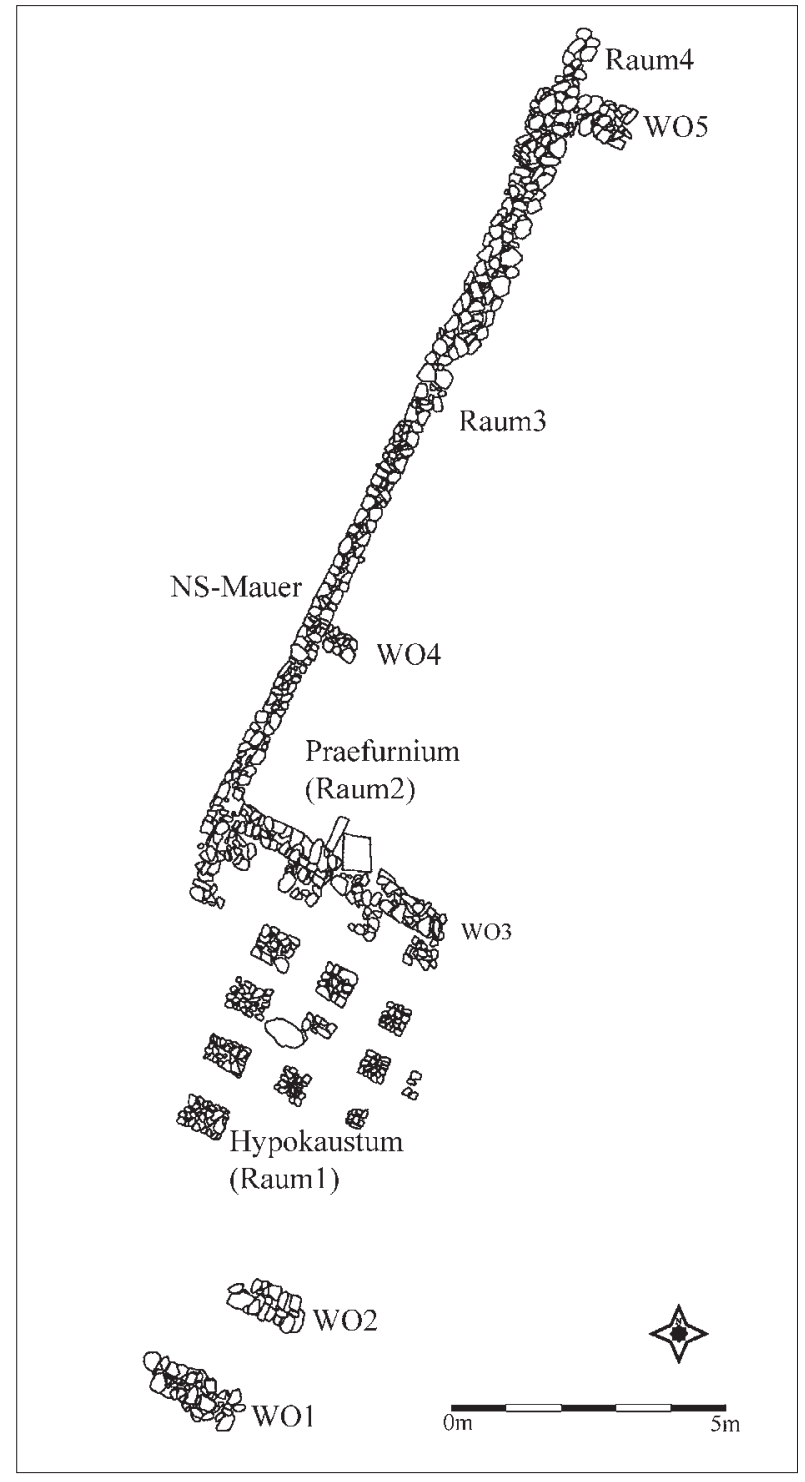

12 Planzeichnung >Gebäude Nord
Als jüngste Schichtung konnten unter dem rezent gebildeten Humus demnach die Schwemmsande von 1964-1966 festgestellt werden. Darunter folgten Geschiebesteine und weitere Schwemmsande, die von Übermurungen stammten, deren Datierung derzeit nicht möglich ist; sicher belegt sind Überschwemmungen Ende des 16. Jahrhunderts und um 1840 sowie 1882, die vom Debantbach verursacht wurden ${ }^{61}$. Es lässt sich auch nicht mit Sicherheit sagen, wie viele Übermurungen das Gebiet über sich ergehen lassen musste. Nach der Beschreibung der Ruinenstätte durch Johann Putsch, der um 1540 noch Teile der Bauten aufrecht stehend sah, darf von einer großflächigeren Übermurung zwischen 1540 und 1800 ausgegangen werden, wobei kleinere Murenabgänge sicher auch schon vor dessen Besuch möglich sind. Im Schichtablauf sind abwechselnde Sand-, Kiesund Geschiebesteinstraten zu erkennen, die von mehrmaliger Überschwemmung und Murenabgängen zeugen. Allerdings schneiden die unterschiedlichen Schwemmschichten ineinander ein, womit eine Trennung der einzelnen >Katastrophenhorizonte kaum mehr möglich ist. Es ist in diesem Zusammenhang auch festzuhalten, dass die gesamte römische Stadt Aguntum auf einem solchen Schwemmkegel errichtet worden war $^{62}$ und so im Extremfall, wenn die gesamte antike Schichtung den Murenkatastrophen zum Opfer gefallen ist, nicht einmal mehr dieser Schwemmkegel mit Sicherheit von späteren Übermurungen unterschieden werden kann - dies ist vor allem im Norden der Stadt der Fall ${ }^{63}$, trifft aber auch auf Bereiche unmittelbar östlich der hier vorgestellten Gebäude zu.

\subsection{Das nördliche Gebäude (〉Gebäude Nord〈)}

Es konnten hier insgesamt vier hintereinander liegende Räume freigelegt werden (Abb. 12). Der Grundriss ist durch die alles überlagernde nachantike Mure stark in Mitleidenschaft gezogen, sodass teilweise nur noch die untersten Lagen der Mauerfundamente erhalten sind. Dennoch konnte im südlichsten Raum eine Hypokaustenanlage festgestellt werden, die vom unmittelbar nördlich gelegenen Raum aus beheizt worden war. Von den nördlich davon gelegenen Räumen sind nur noch geringe Reste erhalten geblieben. Der Abschluss

${ }^{61}$ Die Nachweise dieser Katastrophen finden sich bei Meyer - Unterforcher (Anm. 3) 7-56.

${ }^{62}$ Dieser weist ein ca. 1,6\%-iges Gefälle von Norden nach Süden auf, was schon von E. Swoboda festgestellt wurde und sich 1994 bestätigte. Bezogen auf die Rollierung beider Hypokaustenanlagen, welche die einzige erhaltene antike Oberkante baulicher Substanz darstellen, konnte ein Niveauunterschied des nördlichen zum südlichen Hypokaustum von etwa $1 \mathrm{~m}$ festgestellt werden. Da ungefähr der gleiche Wert auch von E. Swoboda für das Fundament der Stadtmauer nördlich des Nordturmes und südlich des Südturmes festgestellt wurde, dürfte sich hier tatsächlich der antike Geländeverlauf widerspiegeln.

${ }^{63}$ Dazu Swoboda 1935, der bei der Suche nach der Fortsetzung der Stadtmauer im Norden nur noch Geschiebesteine antrifft. 


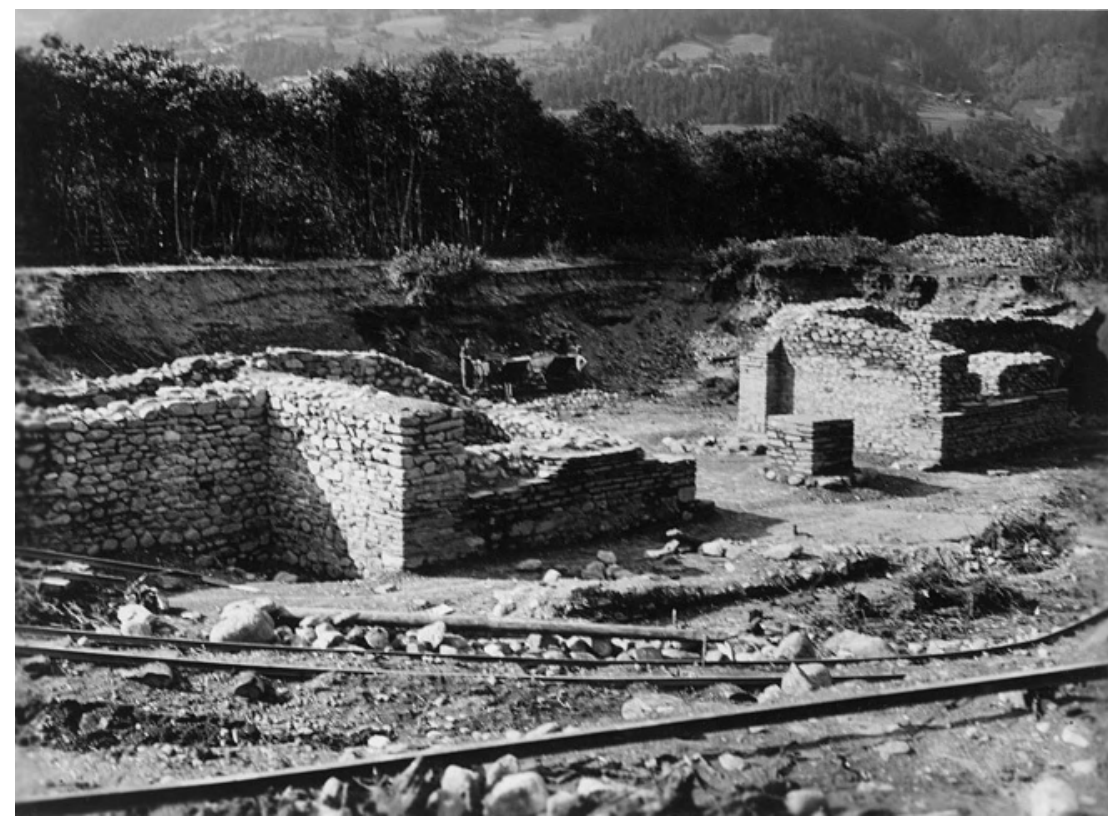

13 Die Toranlage und die östlich davon ausgegrabene Fläche während der Arbeiten E. Swobodas (Blick von Südosten)

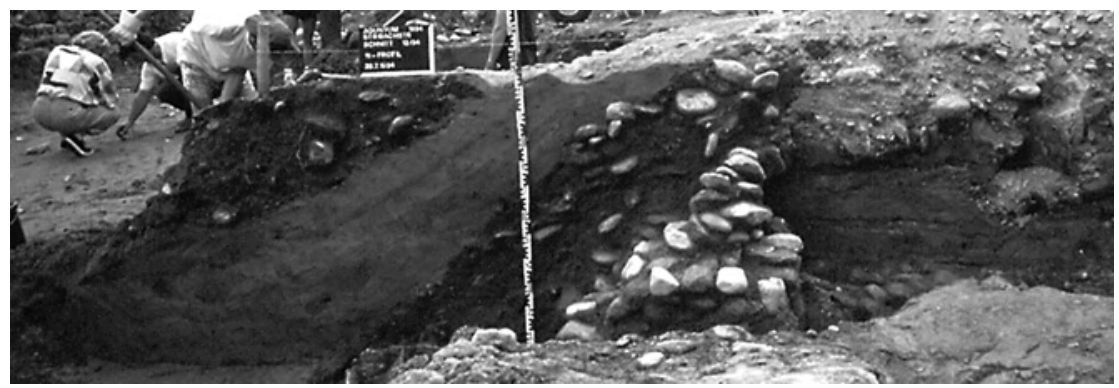

14 Grabungskante der Arbeiten E. Swobodas und daraufliegender Schwemmsand (helle Färbung) bei der Freilegung 1994

des Gebäudes nach Osten hin konnte nicht ergraben werden, da sich auf der anschließenden Böschung eine moderne Verbauung (Grabungshaus aus den Fünfzigerjahren) befindet.

Von Erich Swoboda wurde ein kleiner Teil dieses Bereichs bereits bei der Freilegung des Stadttores angegraben (Abb. 13), aber nicht dokumentiert; die Böschungskanten seiner Grabungen waren 1994 noch klar zu erkennen (Abb. 14). Einige Mauerreste im Schnitt 12/94 und in dessen Süderweiterung (Abb. 15) sind zu gering, um zur Rekonstruktion des Grundrisses herangezogen werden zu können (WO 1 und WO 2); ihre Interpretation ist unklar, da es sich um einen Gebäudeteil oder - aufgrund der Maße wahrscheinlicher einen Gehsteig handeln könnte.

\subsubsection{Das Hypokaustum}

Das Hypokaustum wird im Norden von einer Mauer begrenzt, in die das Präfurnium eingelassen war, und auch ein Teil der westlichen Begrenzung ist noch erhalten. Der Rest dieses Raumes ist der Murenzerstörung zum Opfer gefallen. Im Hypokaustum fand sich unter dem Murenmaterial feiner, brauner Sand, an dessen Unterkante Tubulibruch liegt. Der braune Sand liegt auch unter den wenigen erhaltenen Gewölben des Hypokaustums und füllt diese bis zum Scheitel auf. Unter diesem Auffüllmaterial konnten eine dünne, schwarze Schicht, von der Benützung der Heizanlage stammend, sowie grober, grauer Sand, wobei es sich hier um 


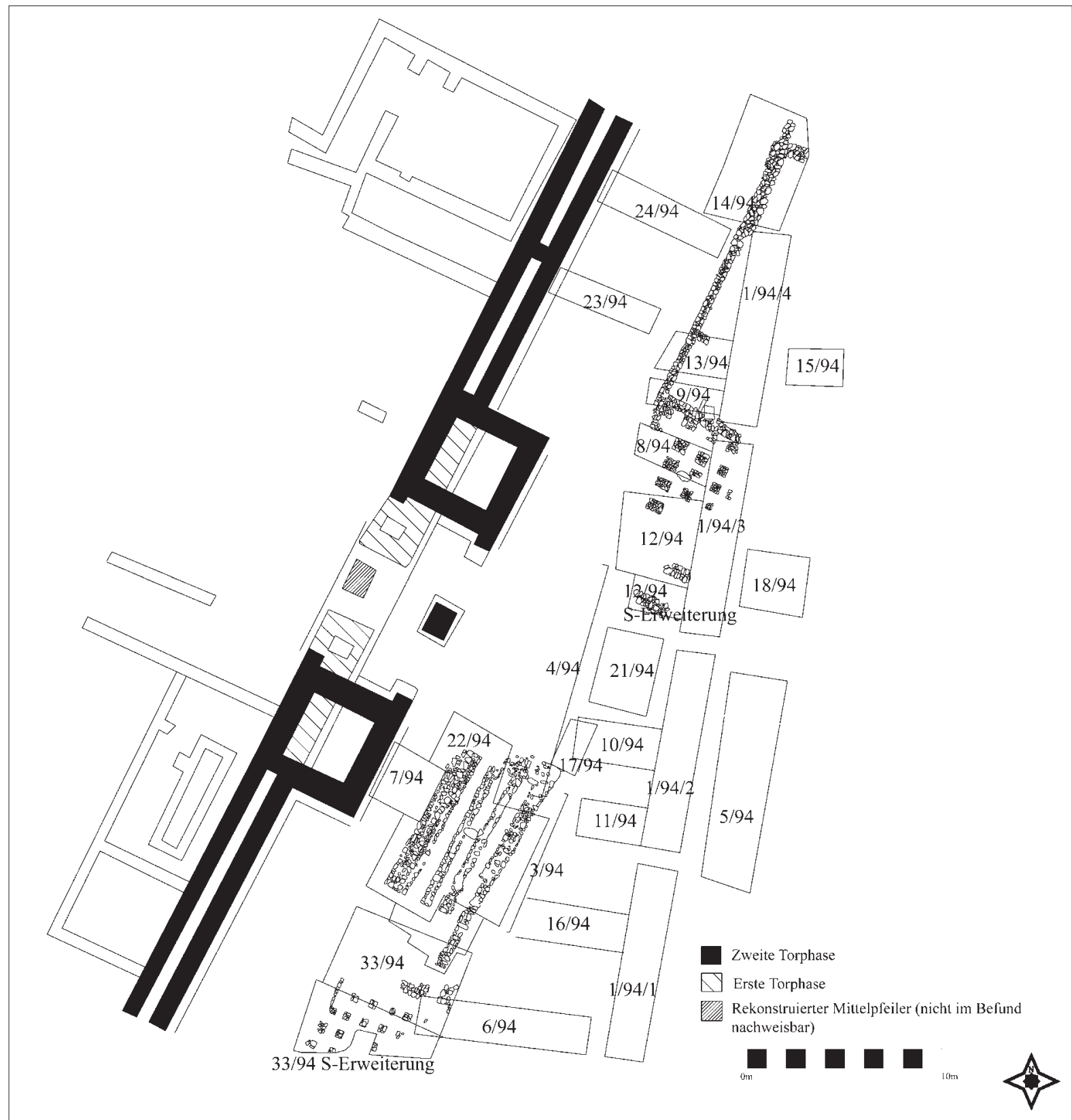

15 Schnittplan der Grabung 1994 mit den freigelegten Gebäuden und den beiden Torphasen auf Grundlage der Planzeichnung E. Swobodas (s. Abb. 6)

den vergangenen Mörtelboden handelt, festgestellt werden. Unter dem >Mörtelboden`folgt die Rollierung (Niveau 659,8-659,9 m) aus größeren Bachsteinen (Dm bis zu $30 \mathrm{~cm}$ ). Die Begrenzungsmauern dieses offensichtlich beheizten Raumes waren nicht mehr nachweisbar. Lediglich an der Westseite des Raumes 1 ist neben der das gesamte Gebäude nach Westen begrenzenden Nord-Süd-Mauer noch eine ältere Mauerphase bzw. eine Fundamentierung der Nord-Süd-Mauer entdeckt worden. An einigen Stellen wurde das Material unter der Rollierung untersucht, wobei auch hier Funde aus römischer Zeit in lehmigen, nicht näher zu definierenden Schichten geborgen wurden. Bei den Lehmschichten dürfte es sich wohl um den Untergrund handeln, der zur Vorbereitung des Baus bearbeitet wurde. 


\subsubsection{Raum 2 (Präfurnium)}

In diesem Raum konnte ein in Verbund mit der Mauer WO 3 erbautes Präfurnium festgestellt werden, wobei das Mauerfundament auch unterhalb der 〉Heizöffnung〈 durchlaufend errichtet worden war. Die Heizöffnung selbst besteht aus einem Unterbau aus großen Bachsteinen sowie zwei seitlich begrenzenden Steinplatten, von denen die östliche durch den Druck der auf ihr lastenden Mure umgestürzt ist. Unter einigen Schichten, die im Wesentlichen aus Brandresten bestehen und mit der Benützung des Präfurniums in Zusammenhang zu setzen sind, konnte nur noch die Rollierung dieses Raumes aus Bachsteinen festgestellt werden (Niveau 659,8 m). Auf ihr liegen die Geschiebesteine im nördlichen Raumabschnitt direkt auf. Unter der Rollierung befindet sich das gleiche Material wie in den Fundamentgräben der Gebäudemauern, womit dieses wohl als Bettung für Mauern und Rollierung gedient hat. Da die nördliche Begrenzungsmauer dieses Raumes (WO 4) eine deutliche Baufuge zur durchlaufenden Nord-Süd-Mauer hin erkennen lässt, ist eine Unterscheidung von zwei Bauphasen möglich. Dies bestätigt sich vor allem durch eine unter WO 4 durchlaufende Brandschicht, die an der Nord-Süd-Mauer anliegt. Als Endpunkt der ersten Phase wäre demnach ein Brand anzusehen, dessen Spuren auch an der Westseite des Gebäudes noch festgestellt werden konnten, wobei schon ca. $1 \mathrm{~m}$ westlich des Gebäudes, bedingt durch die Störungen aus den DreiBigerjahren, die antike Schichtung ausreißt.

\subsubsection{Die Räume 3 und 4}

In geringen Resten konnten auch noch zwei weitere Räume dokumentiert werden, deren Trennmauer (WO 5), wiederum bedingt durch die Murenzerstörung, nur noch sehr fragmentarisch erhalten ist. Auch ist festzuhalten, dass die Nord-Süd-Mauer nördlich von WO 5 nur noch in ihrem Fundament erhalten ist. Unter dem Murenschotter konnten im Bereich nördlich von WO 4 lediglich die Mauerreste sowie stellenweise eine Brandschicht festgestellt werden, die eventuell mit dem oben erwähnten Brandhorizont identisch ist. Die Mauer WO 5 liegt mit ihrem Fundament in einer braunen Sandschicht, die sich direkt unterhalb des Brandhorizonts befindet.

\subsubsection{Gesamtbetrachtung Gebäude Nord}

Die Nord-Süd-Mauer ist als ältestes Bauglied dieses Gebäudes anzusehen. An der Mauer WO 3 befindet sich unterhalb des Präfurniums eine frühere Mauerphase, die in einem Zug mit der Nord-Süd-Mauer errichtet wurde. In einem späteren Arbeitsschritt sind das Präfurnium eingebaut und die Mauer WO 3 erneuert worden, wobei nun nur noch die untersten Steinlagen mit der Mauer in Verbindung standen, während die oberen Steinreihen neu geschlichtet wurden und eine Fuge zur Nord-Süd-Mauer hin aufwiesen. Eine weitere Baufuge ist in der Mauer an der Stelle zu bemerken, an der die ältere Mauer WO 3 nach Osten abbiegt. Der mit Hypokausten beheizte Raum muss demnach einen späteren Anbau darstellen. Ebenso ist die Mauer WO 4 erst später angebaut worden, was sich anhand der unter ihr durchziehenden, an der Nord-Süd-Mauer anliegenden Brandschicht beweisen lässt. Die Begrenzungsmauer WO 5 hingegen dürfte von Beginn an mitgeplant gewesen sein, da hier die Brandschicht erst nach Errichtung der Mauer entstanden ist.

Damit können aus dem wenigen Erhaltenen zwei Benutzungsphasen herausgelesen werden, wovon die erste durch einen Brand beendet worden war. Diesem Brand folgte ein Neuaufbau der Räumlichkeiten mit der Erweiterung durch einen beheizten Raum im Süden, was auch Veränderungen in der Bausubstanz nördlich dieses Raumes mit sich führte, da hier nun ein Präfurnium eingebaut wird. Leider ist in den Räumen 3 und 4 fast nichts mehr von der antiken Schichtung erhalten, sodass außer dem Brandhorizont ${ }^{64}$, der nur noch direkt an den Mauerresten greifbar ist, über die Art der Nutzung dieser Räume nichts ausgesagt werden kann. Auch der Gesamtgrundriss des Gebäudes bleibt unklar, da die Grabung aufgrund der Böschung mit ihrer modernen Verbauung nicht weiter nach Osten geführt werden konnte.

Das `Gebäude Nord` wird schließlich recht bald aufgegeben, was die Auffüllung der Hypokaustenanlage mit zum Zeitpunkt der Freilegung feinem, braunem Sand belegt. Dieser füllt die Hypokausten dort, wo diese erhalten geblieben sind, bis zu ihrem Gewölbescheitel auf und liegt über den zerschlagenen Tubuli

\footnotetext{
${ }^{64}$ Die relativchronologische Einordnung dieses Brandhorizonts (s. u. Schicht 22) war nicht eindeutig möglich, sodass lediglich seine Beziehung zu Teilen des Gebäudes bekannt ist.
} 
der Wandheizung sowie dem Mörtel, der beim Entfernen der Tubuli abgeschlagen wurde. Meines Erachtens handelt es sich hier am ehesten um eine intentionelle Auffüllung der Hypokaustenanlage zum Zeitpunkt der Aufgabe des Gebäudes. Dafür sprechen die sorfältige Auffüllung des gesamten Heizgewölbes bis an seine Oberkante mit recht homogenem Material sowie die Schichtabfolge von Tubuli mit Mörtel in den unteren Schichten und Auffüllmaterial darüber. So wäre es vorstellbar, dass die Tubuli, gesamt immerhin ca. $30 \mathrm{~kg}$ Ziegel- und Tubulibruch allein in den von der Übermurung weitgehend verschont gebliebenen Bereichen, von den Wänden abgeschlagen und mit dem dabei abbröckelndem Mörtel in das Hypokaustum geschüttet worden waren. Eine nicht ganz außer Acht zu lassende Möglichkeit wäre aber auch die Aufgabe des Gebäudes nach einer Überschwemmung, wofür vor allem die Tatsache spricht, dass solche im Gebiet von Aguntum recht häufig waren und der das Hypokaustum auffüllende feine Sand durchaus auch als Schwemmsand angesehen werden kann. Welche Umstände schließlich auch immer zur Aufgabe des Gebäudes geführt haben mögen, es ist aus dem Fundmaterial des `Gebäudes Nord`darauf zu schließen, dass dies noch vor Beginn des 3. Jahrhunderts $\mathrm{n}$. Chr. erfolgt sein muss.

\subsubsection{Relativchronologie des >Gebäudes Nord،}

Es wurde von mir bei der Beschäftigung mit der Grabung `Stribachweg 1994^laufend eine Matrix der Schichtabfolge aus allen Tagebuchaufzeichnungen und der zeichnerischen sowie photographischen Dokumentation erstellt (Abb. 16). Diese hilft den relativchronologischen Ablauf zu fassen und gestattet eine $\mathrm{Zu}$ ordnung der Funde an die einzelnen Schichten. Da die Grabung im Jahr 1994 aber nicht mit einer begleitenden Dokumentation mittels Harris-Matrix durchgeführt wurde, muss die nun dargestellte Matrix mangelhaft bleiben. Zwar wurde während der Grabung sehr wohl nach Schichten vorgegangen, die Aufzeichnungen beschränkten sich aber auf die wesentlichen Schichtzusammenhänge, was für eine Interpretation und Fundzuordnung durchaus ausreichend ist. Um eine wissenschaftlich gesehen korrekte Harris-Matrix zu erstellen, müssten aber alle direkten Schichtzusammenhänge bekannt $\operatorname{sein}^{65}$, wofür sich schon eine nach Grabungsschnitten organisierte Grabung, wie die hier behandelte, nicht eignet. So ist die im Folgenden dargestellte Relativchronologie zwar in sich richtig, genügt aber nicht den Anforderungen, um eine wissenschaftlich korrekte Matrix darzustellen, da der eine oder andere Schichtzusammenhang nicht mehr ermittelt werden konnte ${ }^{66}$.

\subsubsection{Absolutchronologische Aussagen zu >Gebäude Nord}

Insgesamt stammen 57,5\% des gesamten antiken Fundmaterials ${ }^{67}$ der Grabung >Stribachweg 1994 «aus dem Bereich 〉Gebäude Nord〈, allerdings ist nur ein Teil davon mit Sicherheit den antiken Straten zuzuweisen, während das restliche Material im Murengeschiebe über den Bauresten und so aus dem Befundzusammenhang gelöst aufgefunden wurde.

\footnotetext{
${ }^{65}$ Grundlegend dazu E. C. Harris, Principles of Archaeological Stratigraphy (London 1979).

${ }^{66}$ Insbesondere ist damit die zeitliche Gleichsetzung (durch hochgestellte Zahlen zu erkennen) der Schichten 11 und 35 sowie 12 und 34 gemeint, die auf logischen Schlussfolgerung, und nicht auf eindeutige Dokumentation der Schichtenabfolgen zurückgeht. So ist die Schicht von Brandmaterial aus dem Präfurnium (35) sicher gleichzeitig mit der Rußschicht in der Hypokaustenanlage (11) entstanden, ohne dass der stratigraphische Beweis dokumentiert wäre. Gleiches gilt für die Errichtung der Hypokaustenpfeiler (12), die notwendigerweise gemeinsam mit dem Präfurnium (34) erbaut wurden. Die sonstigen in derselben horizontalen Ebene angeordneten Schichten sind in ihrer Entstehung nicht als gleichzeitig anzusehen, sondern könnten lediglich in einer gemeinsamen Phase entstanden sein. - Des Weiteren wurden Interfaces nur soweit aufgenommen, als sie eindeutig dokumentiert waren. Man könnte durchaus noch weitere Interfaces einziehen (wie etwa Interface Murenzerstörung oder Interface der gesamten Hypokaustenanlage vor der Verfüllung), allerdings begäbe man sich damit auf recht unsicheres Terrain, zumal die entsprechende Dokumentation nach Vorgaben der Harris-Matrix nicht vorhanden ist. - Um einen anderen möglichen Kritikpunkt anzusprechen, sei darauf hingewiesen, dass die Matrix natürlich nicht nach unten offen sein sollte, sondern im Idealfall mit dem geologischen Untergrund endet. Dies war hier einmal aufgrund der fehlenden Grabungsergebnisse in einigen Bereichen nicht möglich, und zum anderen ist es in dem - wie erwähnt - mehrfach übermurten Gebiet in Aguntum sehr schwierig, mit Sicherheit festzustellen, wann man wirklich geologische Schichtung ohne menschliche Spuren erreicht hat.

${ }^{67}$ Insgesamt kommen aus der Grabung >Stribachweg 1994^ 631 antike Keramik- und Glasfragmente (sicher zu einem Gefäß gehörige Fragmente sind als ein Stück gerechnet) und 67 neuzeitliche Gefäße.
} 


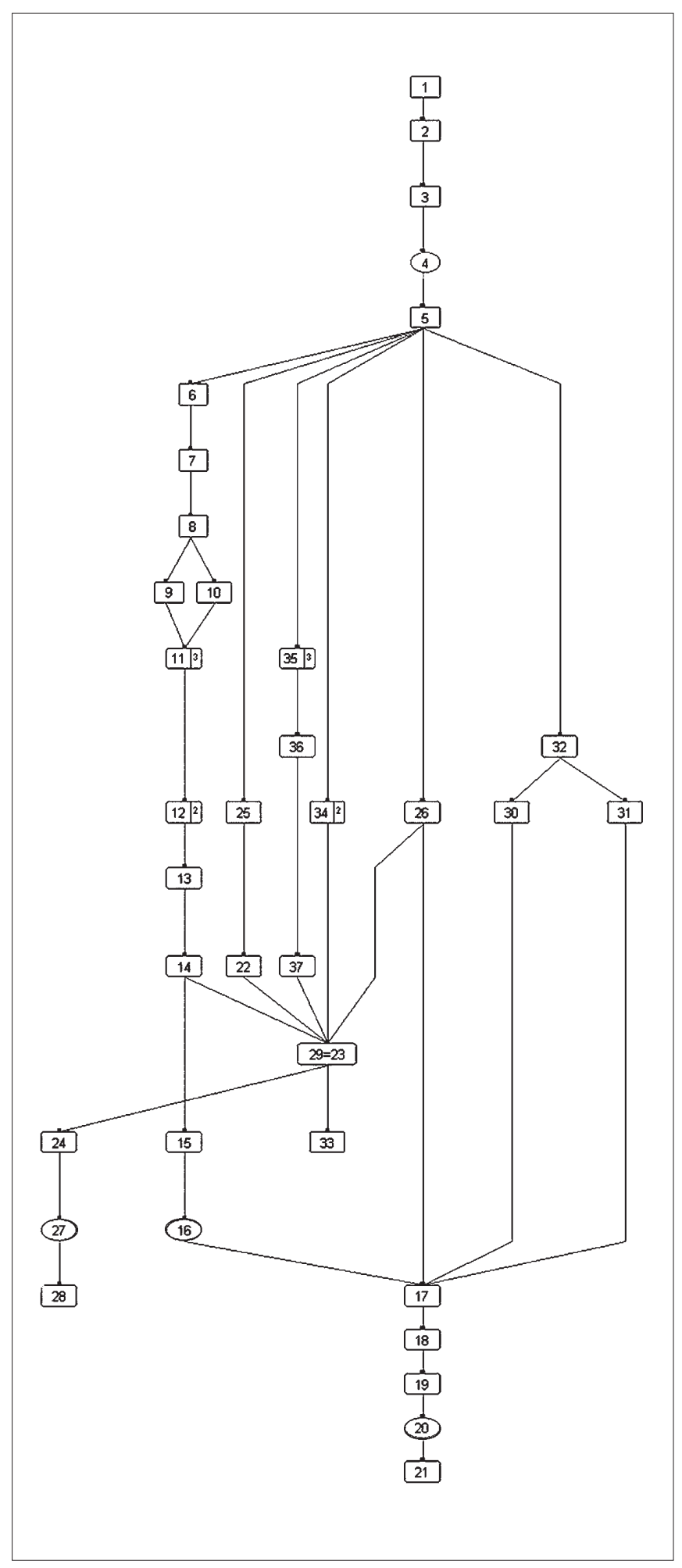

\section{Schichtbezeichnungen ${ }^{68}$}

1 rezenter Humus

2 Sandablagerung der Überschwemmung in den Sechzigerjahren

3 Aufbereitung der Grabungsfläche in den Dreißigerjahren sowie darauf gebildeter Humus

4 Interface der Eingriffe unter Erich Swoboda

5 Murenmaterial

sandige Erde

7 grober, grauer Sand (Versturzmörtel)

8 feiner, sandiger Lehm (Fundmaterial Abb. 22).

9 grober Sand mit Tubulibruch

10 Schotter

11 schwarze Rußschicht über dem Boden des Hypokaustums

12 Hypokaustenpfeiler in Raum 1

13 Boden Raum 1

14 Rollierung Raum 1

15 graubrauner Sand und Kies

16 Interface kleine Grube

17 dunkelbrauner Sand und Kies

18 sehr feiner, heller Sand

19 graugelber Sand mit großen Steinen

20 Interface graugelber Sand mit großen Steinen

21 Murenschotter

22 schwarze Brandschicht (Zerstörungshorizont?) (Fundmaterial Abb. 18. 19)

23 Nord-Süd-Mauer

24 grauer Lehm (Verfüllung Fundamentgrube NordSüd-Mauer und Unterlage der Rollierung) (Fundmaterial Abb. 17)

25 Mauer WO 4

26 Mauer WO 5

27 Interface Fundamentgrube Nord-Süd-Mauer

28 brauner Lehm mit rostfarbenen Einschlüssen

29 Mauer WO 3

30 Mauer WO 1

31 Mauer WO 2

32 Rollierung zwischen WO 1 und WO 2

33 ältere Phase der Nord-Süd-Mauer bzw. Fundamentierung

34 Präfurnium

35 schwarze Schicht im Präfurnium (Fundmaterial Abb. 20. 21)

36 rote Schicht im Präfurnium

37 Rollierung von Raum 2

16 Schichtabfolge/Matrix des >Gebäudes Nord

\footnotetext{
${ }^{68}$ Die Benennung der Schichten stammt mit Ausnahme der Interfaces aus den Grabungstagebüchern und zeichnerischen Dokumentationen der Grabung >Stribachweg 1994^.
} 

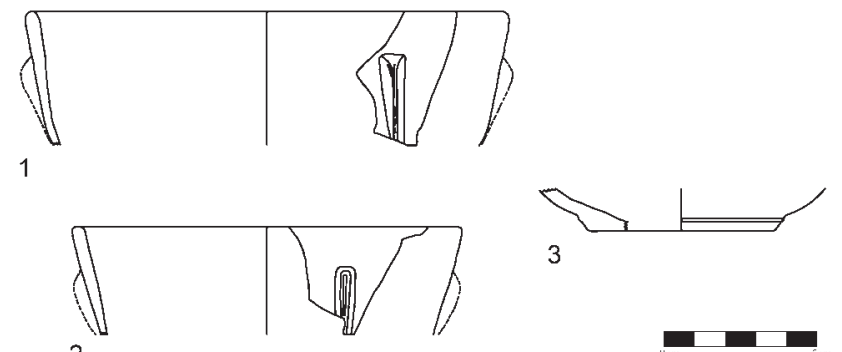

17 Randstücke zweier gläserner Rippenschalen (1. 2) und ein Bodenstück einer Feinkeramik (3) aus Stratum 24 (Bauvorbereitung). M. $1: 3$

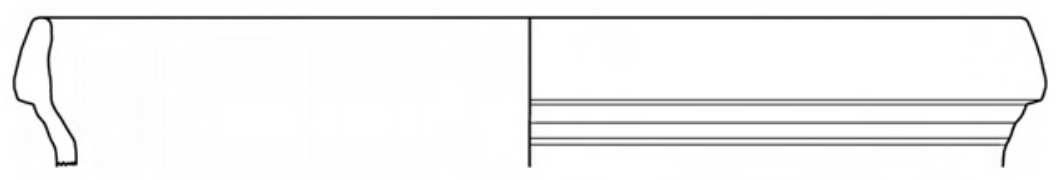

14

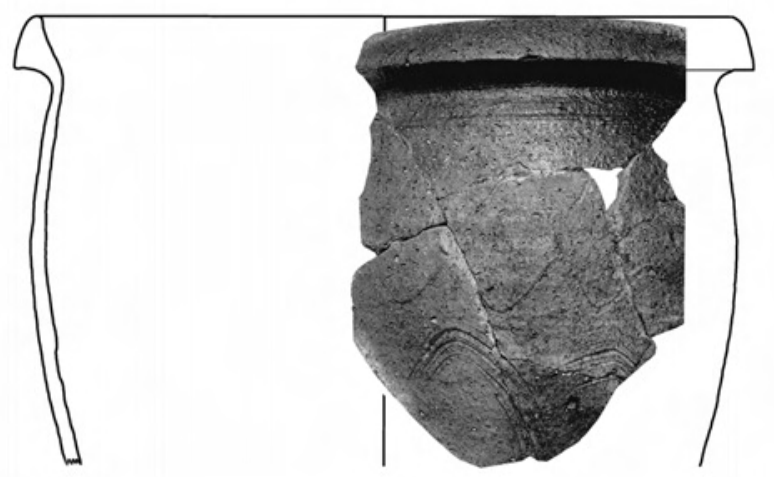

15

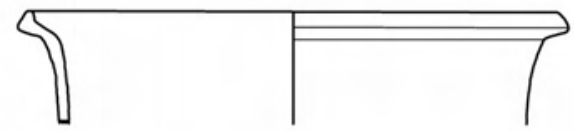

16

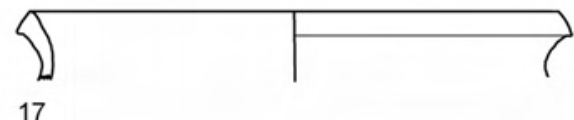

18

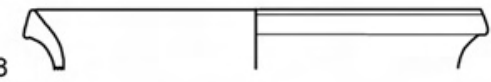

18 Randstücke eines Auerbergtopfes (14) und grautoniger norischer Gebrauchskeramik (15-18) aus Stratum 22 (Brandschicht). M. $1: 3$ 

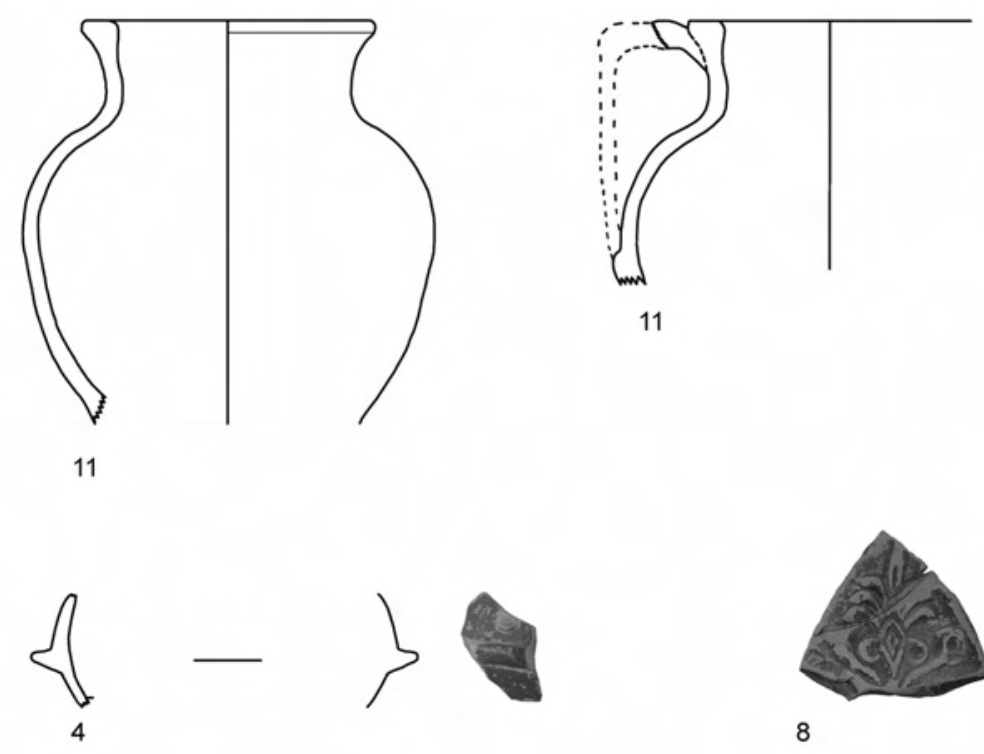

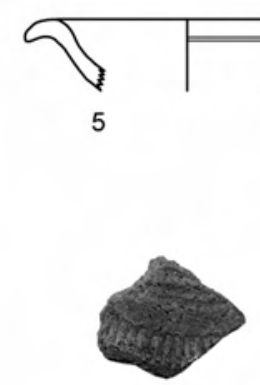

12

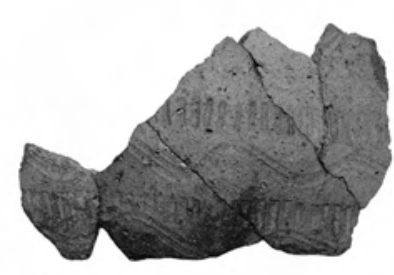

13

19 Fragmente eines grautonigen Kruges (11), Wand- (4) und Randstücke (5) italischer Terra Sigillata, Lampengrifffragment (8) und verzierte Wandstücke grautoniger Gebrauchskeramik (12.13) aus Stratum 22 (Brandschicht). M. $1: 3$

Die ältesten Straten 17-21 und 28 lieferten kaum Fundmaterial und keine datierbaren Fragmente. Den im Folgenden nicht angeführten Straten sind keine datierbaren Fundstücke zuzuweisen, was daran liegt, dass diese nur in räumlich eng begrenzten Bereichen festgestellt wurden, die Menge an aus diesen Straten geborgenem Fundmaterial daher äußerst gering ist. Stratum 24 (grauer Lehm) befindet sich im Fundamentgraben der Nord-Süd-Mauer sowie unterhalb der Rollierung als >Aufbereitung ‘ für dieselbe. Das Fundmaterial aus diesem Bereich umfasst zwei gläserne Rippenschalen sowie ein zur Feinkeramik zu zählendes Bodenstück (Abb. 17). In ihrer Datierung reichen diese Fragmente von der zweiten Hälfte des 1. Jahrhunderts $n$. Chr. bis zur ersten Hälfte des 2. Jahrhunderts n. Chr. Aus der Brandschicht (Stratum 22) stammen sowohl Fragmente von Glas, Gebrauchskeramik (Abb. 18), verzierten Wandstücken, eines Kruges und italischer Sigillata als auch ein Stück einer Firmalampe Loeschcke X sowie einer weiteren Lampe der Form Loeschcke III (Abb. 19). Die Datierung reicht auch hier von der zweiten Hälfte des 1. Jahrhunderts n. Chr. bis zur Mitte des 2. Jahrhunderts n. Chr. Aus den Benutzungsschichten des Präfurniums (Straten 35-36 - das Fundmaterial wurde hier nicht getrennt) sind neben einigen Fragmenten von Gebrauchskeramik (Abb. 20) auch eine Terra-Sigillata-Schüssel, Fragmente eines sog. Soldatentellers sowie eines weiteren Tellers zu nennen (Abb. 21), die auf die Mitte des 2. Jahrhunderts n. Chr. verweisen. Im Auffüllmaterial (Stratum 8) des Hypokaustums ist lediglich Gebrauchskeramik (Abb. 22) zu finden, die in ihrer Datierung grob in das 2. Jahrhundert n. Chr. weist. 


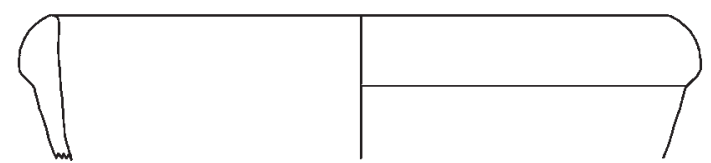

19

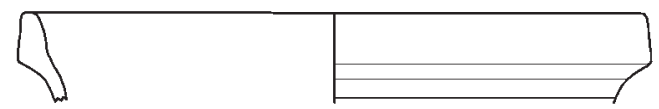

20

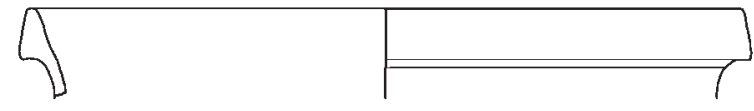

21

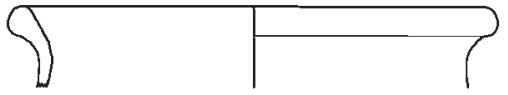

22

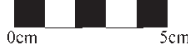

20 Randstücke grautoniger norischer Gebrauchskeramik aus den Straten 35-36 (Benutzung des Präfurniums). M. $1: 3$

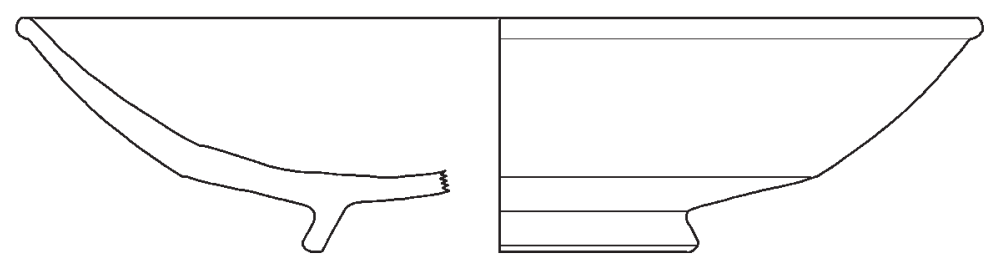

6

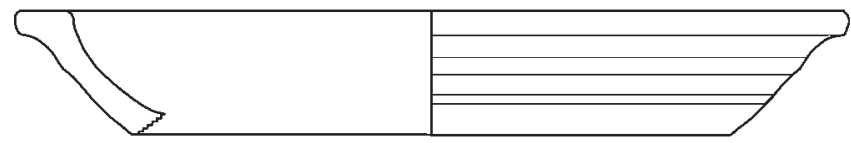

9

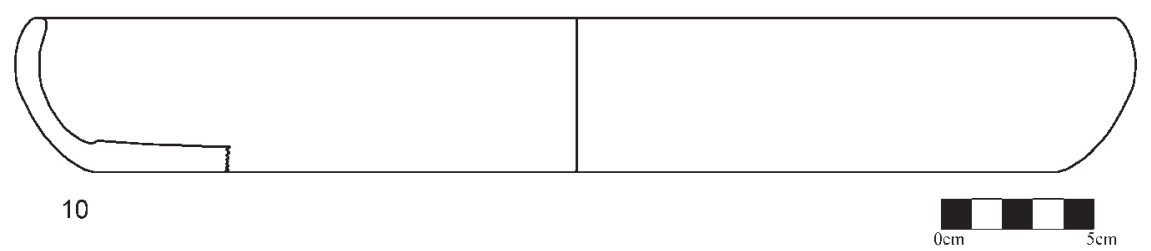

21 Ganzformen einer Terra Sigillata (6), eines engobierten Tellers (9) und eines sog. Soldatentellers (10) aus den Straten 35-36 (Benutzung des Präfurniums). M. $1: 3$ 

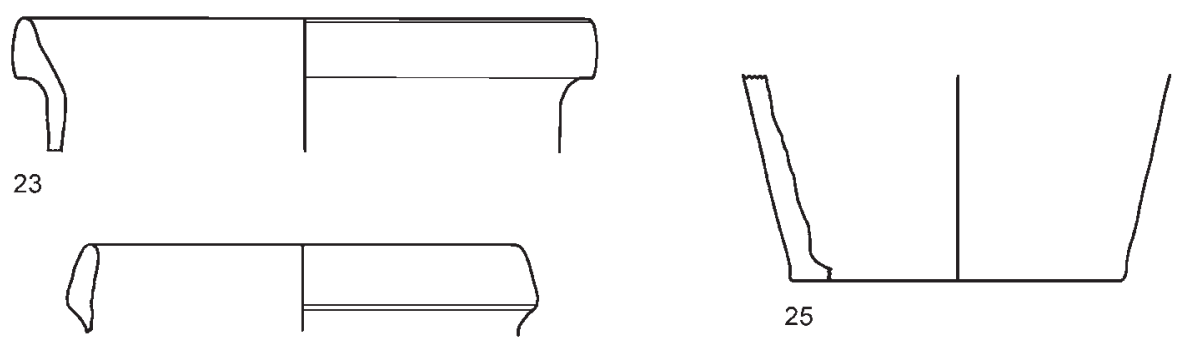

24

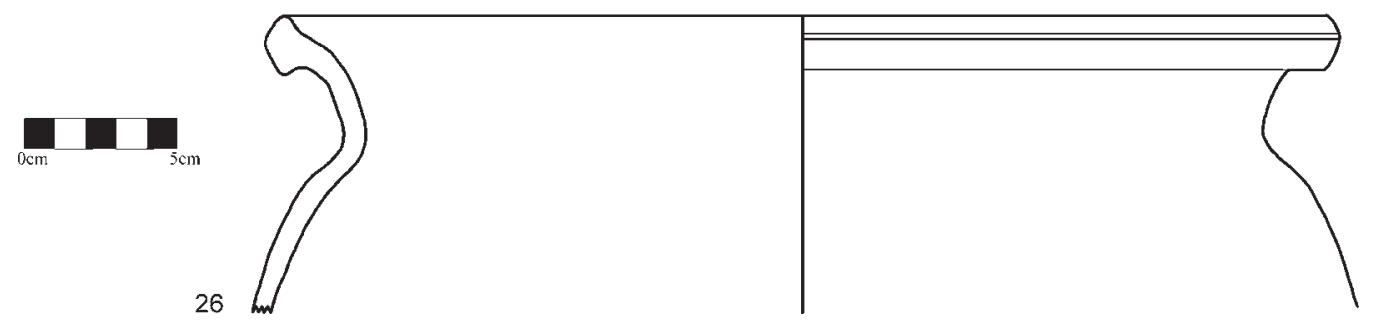

22 Randstücke (23. 24. 26) und Bodenstück (25) grautoniger norischer Keramik aus Stratum 8 (Auffüllmaterial). M. $1: 3$

Mit aller Vorsicht, die der geringe Umfang der stratifizierten Funde gebietet, kann eine erste Bauphase des Gebäudes gegen Ende des 1. Jahrhunderts n. Chr. vermutet werden. Der Schadensbrand ist in der ersten Hälfte des 2. Jahrhunderts $\mathrm{n}$. Chr. anzusetzen, da die darauffolgenden Umbauarbeiten noch vor der Mitte des Jahrhunderts abgeschlossen wurden. Für die Datierung der Auffüllung des Gebäudes besitzen wir nur geringe Evidenz. Spätestens während der ersten Hälfte des 3. Jahrhunderts n. Chr. scheint das Gebäude allerdings nicht mehr in Verwendung zu sein. Dies bestätigt sich dadurch, dass auch der Schwerpunkt des Gesamtfundmaterials eindeutig im 2. Jahrhundert n. Chr. liegt und mit Sicherheit dem 3. Jahrhundert n. Chr. zuzuordnende Funde fehlen. Die Übermurung des 1994 ergrabenen Bereichs dürfte eine neuzeitliche Zerstörung darstellen, was der Fund eines braun glasierten Keramikfragments zusammen mit antikem Material im den Mauerdurchlass des Präfurniums teilweise auffüllenden Murenschotter bestätigt.

\subsection{Das südliche Gebäude (〉Gebäude Süd $`)$}

\subsubsection{Die >Fundamentstreifen<}

Der nördliche Teil dieses Bauwerks wurde schon von Erich Swoboda freigelegt, wobei die sog. Fundamentstreifen bereits während der Grabungskampagne aufgemauert wurden (Abb. 23). Südlich davon konnten 1994 ein weiterer mittels Hypokaustenanlage beheizter Raum sowie das nordöstlich gelegene, zugehörige Präfurnium festgestellt werden. Im mittleren Bereich dieser Anlage, südlich an die >Fundamentstreifen ২ anschließend, wurden neuzeitliche Störungen angetroffen, die wahrscheinlich in den Dreißiger- oder Fünfzigerjahren entstanden waren (Abb. 24). Die modern errichteten Mauerzüge liegen teilweise mit ihren untersten Steinlagen direkt auf der Rollierung (Niveau ca. 658,8 m) dieses Gebäudeteils auf. Da darunter keine antiken Mauerstrukturen erhalten geblieben sind und eine eventuelle Fundamentierung nicht ergraben wurde, gestaltet sich die Interpretation der >Fundamentstreifen` schwierig. Es ist in diesem Zusammenhang nicht auszuschließen, dass es sich bei ihnen um durch die Übermurung umgestürzte Hypokaustenpfeiler handeln könnte, die wegen der Aufmauerung noch während der Grabung nicht ausreichend untersucht wurden ${ }^{69}$. Dies

\footnotetext{
${ }^{69}$ Es findet sich bei Swoboda 1935, 61-62 auch der Hinweis, dass der gesamte Bereich über diesem Bau vollständig von Murenschotter überlagert war, was wahrscheinlich macht, dass der antike Zustand dieses Gebäudes nur noch sehr schwer zu erkennen war.
} 


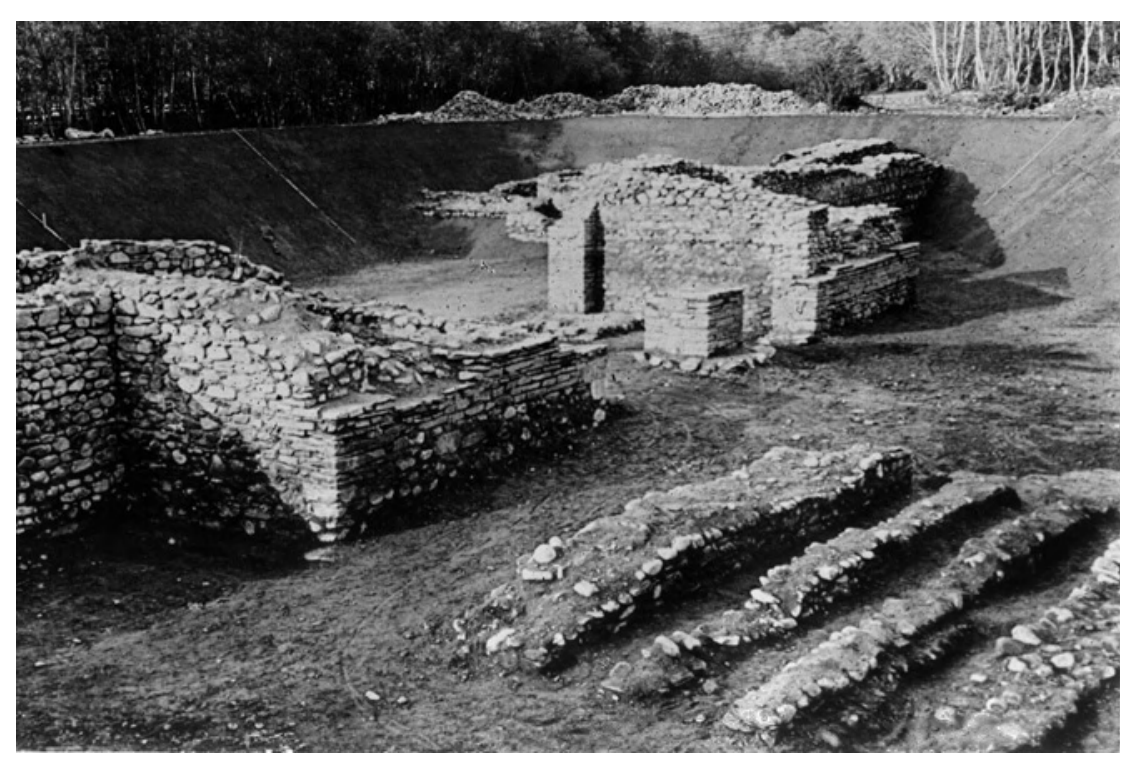

23 Toranlage und `Gebäude Süd ^nach der Freilegung durch E. Swoboda

legt vor allem die Tatsache nahe, dass an einigen Stellen dieser Mauerzüge Steine fehlen und die darüber befindlichen Lagen auf Erdreich ruhen. Geht man aber davon aus, dass es sich hier wirklich um vier Mauerzüge handelt, ließe sich auch in Betracht ziehen, dass es sich um eine Heizanlage, bestehend aus mehreren Heizkanälen, handelt ${ }^{70}$. Da der südliche und nördliche Teil des >Gebäudes Süd` wohl zu ein und demselben Bau gehören, halte ich die Deutung als ursprüngliche Hypokaustenanlage für wahrscheinlicher. Letztlich kann aber nicht eindeutig entschieden werden, wie der antike Befund ausgesehen hat, wahrscheinlich ist jedoch, dass es sich hier um die Reste einer wie auch immer gearteten Heizanlage handelt, und nicht um ein >Streifenfundament

\subsubsection{Das Hypokaustum}

Im 1994 neu ergrabenen Teil des Gebäudes (Abb. 25) ist unterhalb der alles überlagernden Murenschichten stellenweise die Oberkante der Hypokaustengewölbe, die auch hier mit lehmigem, braunem Material verfüllt waren, erhalten geblieben. Unter dieser Verfüllung befanden sich neben sehr wenig Versturzmaterial, das von Hypokaustenpfeilern und -gewölben stammt, auch Tubulibruchstücke sowie die ebenso im >Gebäude Nord ‘ festgestellte schwarze Rußschicht über dem Mörtelboden. Der Mörtelboden ruht auf einer Bachsteinrollierung (Niveau 658,4-658,6 m). Das Auffüllmaterial im Hypokaustum ist - abgesehen von der etwas geringeren Menge an Tubulibruch - von gleicher Zusammensetzung wie im >Gebäude Nord<, sodass auch hier nur eine Interpretation als gewollte Verfüllung oder massive Überschwemmung möglich ist. Die Hypokaustenanlage im südlichen Teil des >Gebäudes Süd « weist nur noch geringe Reste der ehemaligen Begrenzungsmauern auf. So konnte neben Resten der nördlich anschließenden Mauer mit eingebautem Präfurnium lediglich die östliche Steinreihe der westlichen Begrenzungsmauer auf einer Länge von 1,6 m verfolgt werden. Dies ist mit einem Murenverlauf zwischen Stadtmauer und >Gebäude Süd erklären oder auf ältere Grabungstätigkeiten zurückzuführen, wofür an dieser Stelle aber eindeutige Indizien fehlen. Östlich des Gebäudes finden sich massive Murenschichten (Sand-, Kies- und Geröll). Von einer Abschlussmauer war hier nichts mehr festzustellen. Der Abschluss des Gebäudes nach Süden konnte 1994 nicht ergraben werden, da unmittelbar an den Grabungsbereich der Damm der Bundesstraße 100 anschließt. Südlich des Dammes waren im Jahr 1995 im Zuge der Errichtung eines Parkplatzes an dieser Stelle Untersuchungen möglich, wobei allerdings nur der Rest einer Rollierung erkannt werden konnte. Es besteht die Möglichkeit, dass diese Rollierung zu dem Befund nördlich der Bundesstraße 100 gehört, zu belegen ist eine

${ }^{70}$ Derartige Heizanlagen sind aus Aguntum bekannt, etwa in Raum 5 (s. Miltner 1953 sowie Auer [Anm. 60]). 


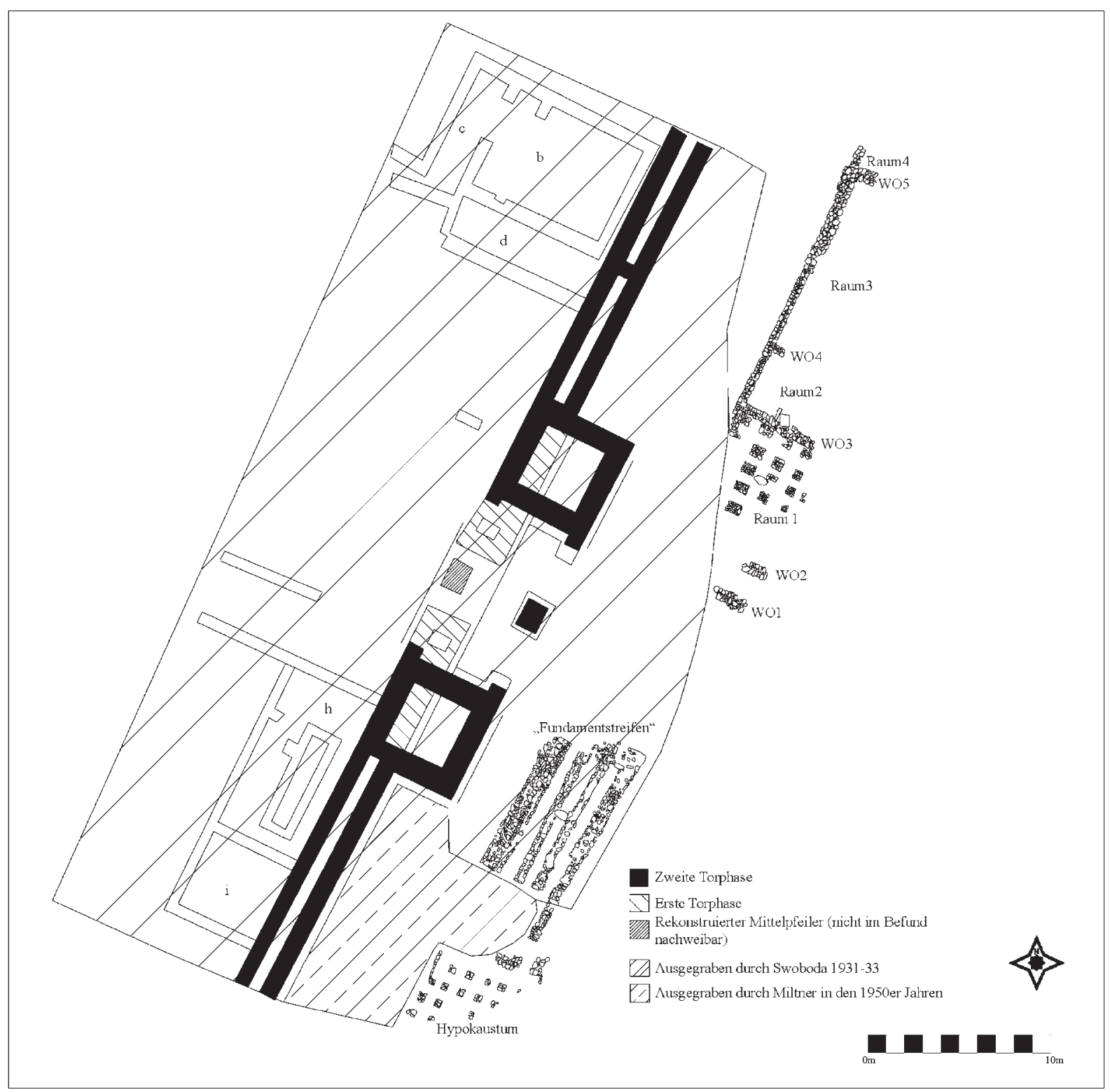

24 Planzeichnung des Torbereichs (auf Grundlage der Planzeichnung E. Swobodas - Abb. 6) und der 1994 freigelegten Gebäude mit Schraffur der Altgrabungsbereiche

solche Annahme derzeit aber nicht. Unterhalb der Rollierung des südlichen Teils von >Gebäude Süd waren noch weitere Steinsetzungen zu beobachten, die vielleicht als Fundamentreste einer älteren Bauphase anzusprechen sind und direkt auf sterilem Material aufliegen. Das Aussehen dieser möglichen früheren Phase bleibt jedoch unklar, da die angesprochene Steinsetzung nur an einer Stelle festgestellt werden konnte. Über diesen Steinlagen war eine Ausgleichsschicht (sandiges Material) aufgebracht worden, die unterhalb der Rollierung der Hauptphase überall zu beobachten war.

\subsubsection{Die `Freifläche` zwischen den `Fundamentstreifen` und dem Hypokaustum}

Im Bereich zwischen dem Hypokaustum und den >Fundamentstreifen`wurden viele neuzeitliche Funde in einer Steinschüttung geborgen, was eine Störung dieses Bereichs in der ersten Hälfte des 20. Jahrhunderts belegt (s. Abb. 24). Unterhalb dieser Störung wurde stellenweise eine dunkle Schichtung festgestellt, die antikes Fundmaterial enthielt und wohl als Benutzungshorizont angesehen werden kann. Unmittelbar darunter 


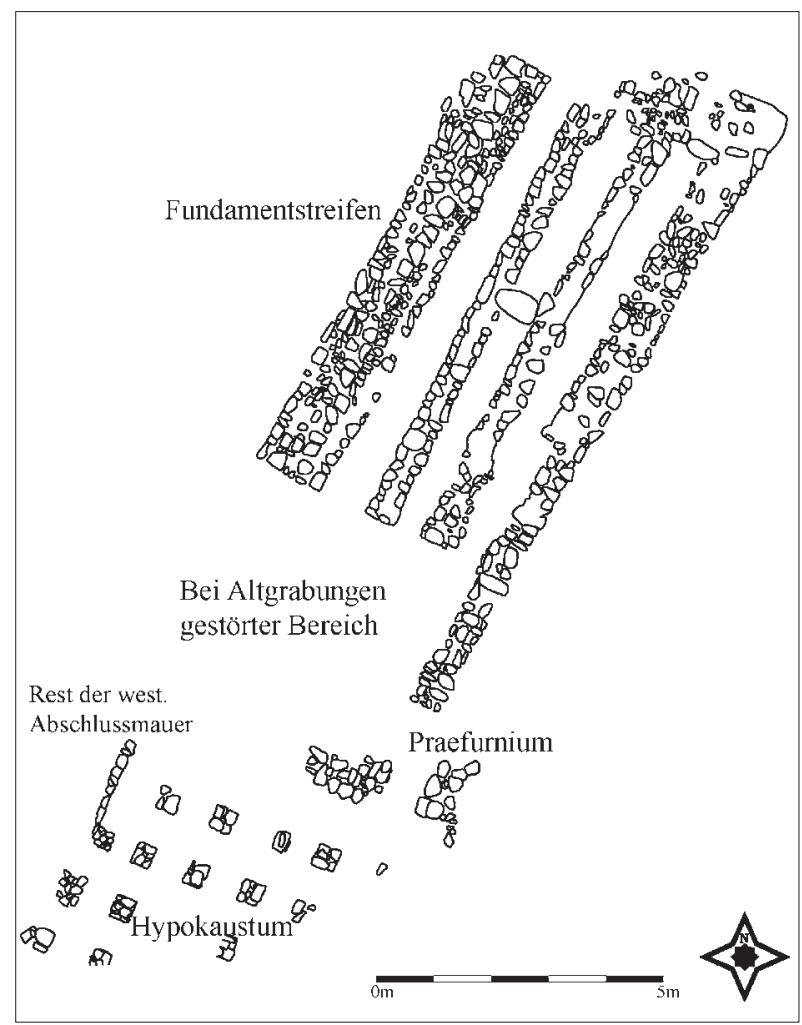

25 Planzeichnung >Gebäude Süd

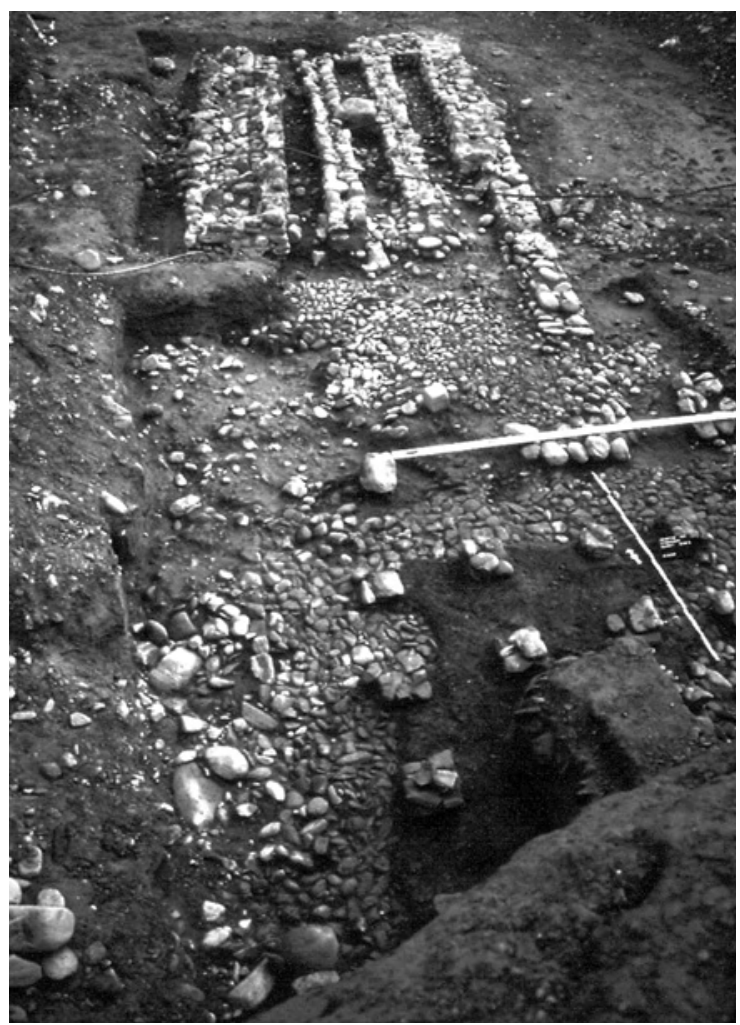

26 Ansicht des >Gebäudes Süd bei der Freilegung 1994 (Blick von Süden)

folgt auch hier eine teils modern gestörte Rollierung, die mit jener der >Fundamentstreifen steht (Abb. 26).

\subsubsection{Relativ- und absolutchronologische Aussagen zu>Gebäude Süd}

Weite Teile dieses Gebäudes sind durch die Grabungen der Dreißiger- und Fünfzigerjahre gestört und konnten für chronologische Aussagen nicht herangezogen werden (Abb. 24). Die Schichtabfolge des >Gebäudes Süd « ist in weiten Teilen dem `Gebäude Nord`sehr ähnlich. Aufgrund des schlechten Erhaltungszustands und der geringen Menge antiken Fundmaterials - 18\% des antiken Fundmaterials, das nur teilweise den antiken Straten zuordenbar ist, - im Bereich des `Gebäudes Süd «äre eine Darstellung der Schichtabfolge in Form einer Matrix nicht aussagekräftig.

In der Rollierung sind einige Amphorenfragmente verbaut, die in ihrer Datierung grob an den Beginn des 2. Jahrhunderts n. Chr. weisen. Aus dem Benutzungshorizont des Präfurniums ist ebenfalls nur ein Amphorenfragment geborgen worden, das in das 2. Jahrhundert n. Chr. zu datieren ist. Der Verfüllung der Hypokausten des >Gebäudes Süd k konnten keine datierbaren Funde entnommen werden, sondern lediglich Ziegelund Tubulisplitt.

Von der Freilegung der $>$ Fundamentstreifen $\prec$ berichtet Erich Swoboda ${ }^{71}$, dass in den »untersten Schichten« (also wohl knapp über der Rollierung) einige Funde geborgen werden konnten. Es handelt sich hierbei um eine Lampe Loeschcke X mit Stempel OCTAVI, einen Dupondius der jüngeren Faustina, ein As des noch als Caesar betitelten Marc Aurel, ein As und einen Sesterz des Hadrian - somit weisen auch die von Swoboda festgestellten Funde in das 2. Jahrhundert n. Chr. Von einer Benutzung der Räumlichkeiten im 2. Jahrhundert $\mathrm{n}$. Chr. kann damit wohl ausgegangen werden, wobei im gesamten Fundmaterial der dem 〉Gebäude Süd ‘ zuzuordnenden Straten keine Funde des 3. Jahrhunderts n. Chr. zu finden sind. Es kann mit

\footnotetext{
${ }^{71}$ Swoboda $1935,31$.
} 
aller Vorsicht angenommen werden, dass dem `Gebäude Süd `ein ähnliches Schicksal wie >Gebäude Nord` beschieden war, nämlich eine Aufgabe des Baus zum Anfang des 3. Jahrhunderts hin.

\subsection{Die Frage nach den Resten der antiken Straße}

Es wurden in der Verlängerung der Stadtmauerdurchfahrt mehrere Grabungsschnitte angelegt, die zur Klärung der Frage nach der Nachweisbarkeit der antiken Straße dienen sollten. Es sind in diesen Grabungsbereichen allerdings keine eindeutig einer Straße zuzurechnenden Schichtungen festgestellt worden, was hauptsächlich mit der starken Übermurung dieses Gebiets und dem fehlenden Anschluss der Straten an die Stadtmauerdurchfahrt zu erklären ist. Eine relativchronologische Schichtabfolge im Sinne einer Harris-Matrix ist für die Gesamtheit der hier erwähnten Schnitte nicht zu erstellen, da diese teilweise weit voneinander entfernt liegen und im späteren Ver-

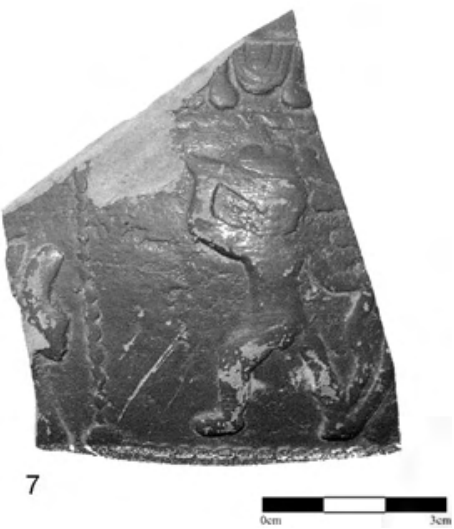

27 Terra-Sigillata-Fragment aus den Benutzungsschichten über dem Fundamentgraben der Stadtmauer. M. $2: 3$ lauf der Grabung nicht miteinander verbunden wurden, sodass eine Gleichsetzung der Schichten der verschiedenen Schnitte unmöglich ist. Da es sich im größten Teil der an dieser Stelle behandelten Bereiche >nur< um die Abfolge kaum fundführender Sand- und Schotterschichten handelt, sind absolutchronologische Aussagen hier nicht möglich. Das Fundmaterial ist sehr spärlich: Aus insgesamt sieben Grabungsschnitten, die zur Erforschung des Straßenverlaufs angelegt wurden, stammen gerade einmal 5,9\% des gesamten antiken Fundmaterials, wobei die eventuellen Begehungshorizonte keine datierbaren Funde beinhalteten. Stellenweise sind sogar in den untersten ergrabenen Murenschichten noch braun glasierte Keramik und Porzellan - so sind 6\% des neuzeitlichen Fundmaterials den erwähnten Schnitten zuzuordnen - zu finden, was von der massiven neuzeitlichen Störung dieser Bereiche zeugt.

\subsection{Der Grabungsschnitt am nördlichen Stadtmauerverlauf}

In Schnitt 24/94 (Abb. 15) sind Reste der antiken Schichtung erhalten geblieben, auch wenn sich hier ebenfalls verschiedene neuzeitliche Eingriffe sowie die nachantike Mure störend auswirken. Es war jedoch möglich, die Fundamentgrube an der Stadtmauer sowie Reste der über derselben liegenden antiken Schichtung zu erkennen. In diesem Grabungsschnitt wurden 7\% des gesamten antiken Fundmaterials geborgen, wobei auch hier nur ein Teil den antiken Schichten zuordenbar ist. Aus den Benutzungsschichten über dem Fundamentgraben der Stadtmauer stammen ein Fragment einer reliefverzierte Sigillata (Abb. 27) des ausgehenden 1. Jahrhunderts n. Chr. sowie ein fragmentiertes Randstück einer Amphore, nicht näher einordenbare grautonige Bodenfragmente und ein Wandstück einer schwarz überzogenen Feinkeramik. Eine nähere Datierung letzterer ist nicht möglich, sie sind aber grob in das 2. Jahrhundert $\mathrm{n}$. Chr. zu setzen. Aus dem unmittelbaren Bauhorizont der Stadtmauer sowie der Fundamentgrube konnten keine Funde geborgen werden. Somit kann aufgrund des Fundmaterials angenommen werden, dass sich die über dem Fundamentgraben der Stadtmauer liegenden Straten im 2. Jahrhundert n. Chr. bildeten.

\subsection{Zusammenfassung und Überlegungen zur Relevanz der Grabung `Stribachweg 1994^ bezüglich der Datierung der Stadtmauer}

Betrachtet man den Stadtplan Aguntums (Abb. 1), so scheint es nahezu zwingend, dass beide untersuchten Gebäude östlich der Stadtmauer erst nach der Errichtung derselben entstanden sind, zumal sie parallel zu der Stadtmauer liegen. Die in einer ersten Phase wohl schon vor der Stadtmauer bestehende Bebauung im Bereich des Atriumhauses sowie die restliche Innenbebauung beiderseits des Decumanus Maximus weisen eine andere Ausrichtung auf, die sich wohl am >vor-stadtmauerzeitlichen< Straßenverlauf orientiert. Wenn aber die 
〉Gebäude Nord 〈 und 〉Südく erst nach Errichtung der Stadtmauer entstanden sind, so mutet es seltsam an, dass sie genau vor den Tortürmen liegen und so jeden repräsentativen Wert derselben enorm schmälern. Aufgrund dieser Überlegung und aufgrund des Fundmaterials vor allem aus `Gebäude Nord`, das in seiner Datierung die zweite Hälfte des 2. Jahrhunderts n. Chr. kaum überschreitet, möchte ich schließen, dass die Gebäude bei Errichtung der Flankierungstürme und der verbreiterten Fahrbahn des Tores aufgegeben wurden. Zu diesem Zeitpunkt wurden sie entweder niedergerissen und die Heizungsanlagen aufgefüllt, um einem eventuellen Einsturz derselben vorzubeugen, oder es kam zu einer Überschwemmung, die zum Anlass für den Umbau des Stadttores und somit für die Aufgabe der unmittelbar vor ihm gelegenen Gebäude genommen wurde.

Somit erbringen die Gebäude vor dem Osttor einen zweifachen Nutzen hinsichtlich der Datierung der Stadtmauer: Zum einen musste die Ummauerung schon bestanden haben, als die Gebäude wohl zu Beginn des 2. Jahrhunderts $n$. Chr. errichtet wurden ${ }^{72}$. Zum anderen dürfte der Umbau der Toranlage erst erfolgt sein, nachdem diese Gebäude gegen Ende des 2. Jahrhunderts bzw. zu Beginn des 3. Jahrhunderts n. Chr. aufgegeben worden waren, wofür allerdings der archäologische Beweis aufgrund des fehlenden stratigraphischen Anschlusses an das Stadttor nicht erbracht werden kann.

\section{Zur funktionalen Deutung der Stadtmauer von Aguntum}

Betrachtet man die nicht parallele Ausrichtung der Innenbebauung am Decumanus Maximus zur Stadtmauer, scheint es nicht unwahrscheinlich, dass die eigentliche Hauptachse der Stadt Aguntum nicht am momentan als >Osttor< der Stadt bezeichneten Eingang liegt, sondern weiter nördlich, etwa an der Straße, die als >Decumanus I sinister benannt ist. Zum einen wird dies durch die älteren Bauphasen unter der großen Therme $^{73}$, die annähernd parallel zur Stadtmauer liegen, indiziert, zum anderen liegen auch einige Gebäude des >Handwerkerviertels $<$ am >Decumanus I sinister annähernd parallel zur Stadtmauer. Ein weiteres Indiz für eine Hauptachse nördlich des heute bekannten >großen Tores` ist die Anlage der Trennwände innerhalb der Stadtmauerschalen in bestimmten Abständen. Die Zählung dieser Abstände muss an einem bestimmten Punkt beginnen, wobei ein ursprünglich mitgeplantes Tor als Anfangspunkt gut denkbar wäre. Die Trennwände liegen, wie schon Franz Miltner erwähnt ${ }^{74}$, keineswegs symmetrisch zum Osttor der Stadt und auch nicht zu dessen kleinerem Vorgängerbau. Vielmehr scheint eine Zählung der Abstände von einer - zum momentanen Zeitpunkt nur hypothetischen - Hauptachse im Norden ausgehend wahrscheinlich. Interessant ist hier auch, dass sich die Nordwange des ursprünglich mitgeplanten Nebentores 1 (NT 1) genau in die Zählung der Abstände zwischen den Trennwänden einfügen lässt.

Für die Bestimmung der Funktion der Aguntiner Stadtmauer ist die Klärung der Frage nach einem in der ersten Bauphase mitgeplanten Haupttor unerlässlich, da sich vor allem die in der bisherigen Forschung oft genannte repräsentative Wirkung einer Stadtmauer nur mit einem entsprechenden Haupttor erzielen ließe. Die bisher gesicherten, von Anfang an geplanten Tore sind einfache Durchlässe in der Mauer (Osttor und NT 1), die wegen des Fehlens aufgesetzter Türme (wie etwa in Nicopolis ad Istrum ${ }^{75}$, in Rottenburg ${ }^{76}$, dem Hafentor in Köln ${ }^{77}$ oder beim Ost- und Westtor in Trient ${ }^{78}$ ) weder einen allzu großen fortifikatorischen noch repräsentativen Wert besaßen.

\footnotetext{
${ }^{72}$ Eine Bebauung >vor den Toren der Stadt $<$ bald nach Errichtung der Stadtmauer ist nichts Außergewöhnliches. So finden sich z. B. in Arles (M. Droste, Arles - Gallula Roma - Das Rom Galliens, AW Sonderh. [Mainz 2003]) sowie Trient (Ciurletti 2002) bei zu Beginn des 1. Jhs. n. Chr. fertiggestellten Stadtmauern noch im 1. Jh. zahlreiche Gebäude vor denselben. In Arles wird sogar noch im 1. Jh. eine Thermenanlage vor der Stadtmauer errichtet.

${ }^{73}$ Besonders W. Alzinger, Grabung Aguntum 1968, PAR 19, 1969, 18-19 und W. Alzinger, Die Grabungen in Aguntum 1969, PAR 20, 1970, 10-11.

${ }^{74}$ Miltner 1955, 89-90.

75 A. Poulter, Nicopolis ad Istrum. A Roman, late Roman and Byzantine city, JRA Monographs 8 (London 1995).

${ }^{76}$ S. Gairhos, Ad Aeternam Perfectus Sine Vitio Murus. Stadtmauern im römischen Südwestdeutschland, in: D. Planck u. a. (Hrsg.), Imperium Romanum. Roms Provinzen am Neckar, Rhein und Donau (Stuttgart 2005) 195-197.

${ }^{77}$ H. Hellenkemper, The Roman Defences of Cologne - Colonia Claudia Ara Agrippinensium, in: Maloney - Hobley 1983, $20-28$.

${ }^{78}$ Ciureltti 2002.
} 
Damit stellt sich in Bezug auf die Funktionsbestimmung der Aguntiner Stadtmauer zunächst die Frage, aus welchen Beweggründen eine römische Stadt eine Ummauerung erhielt. War es zu Zeiten des Augustus noch üblich, jeder neuen römischen Stadtgründung eine Umfassungsmauer zu bauen ${ }^{79}$, endete dieser >Brauch s schon in der zweiten Hälfte des 1. Jahrhunderts n. Chr. Trotzdem wurden weiterhin Stadtmauern und Tore errichtet, wobei die Erklärungen für diese Bauten vor allem von der zweiten Hälfte des 1. Jahrhunderts n. Chr. bis zur Mitte des 2. Jahrhunderts n. Chr. oft schwer fallen. Diese Ummauerungen werden in einer eher friedlichen Zeit ohne fortifikatorische Notwendigkeit errichtet, was ohne die Datierung begleitende archäologische Evidenz manchmal dazu führte, dass die Mauern in unruhigere Zeiten datiert wurden ${ }^{80}$.

Offensichtlich gab es aber auch noch andere Gründe, eine Befestigungsmauer zu errichten, wobei vor allem die Änderung des Stadtrechts eine wesentliche Rolle gespielt haben dürfte. Wurde eine Stadt zum Municipium oder zur Colonia erhoben, so war es nicht ungewöhnlich, dass dieses neue >Bürgergefühl< in der Errichtung öffentlicher Bauten Ausdruck fand. So erhalten etwa Camulodunum (Colchester) und Glevum (Lincoln) bald nach ihrer Erhebung zu coloniae Stadtmauern ${ }^{81}$. Daneben ist für Aventicum (Avenches $^{82}$, für die Colonia Claudia Ara Agrippinensium (Köln) und die Colonia Ulpia Traiana (Xanten) ${ }^{83}$ die Erhebung zur Colonia ${ }^{84}$ als Grund für die Errichtung der Stadtmauer anzunehmen. Aber auch für einige wenige municipia werden bald nach der Stadtrechtsverleihung datierende Mauerbauten vermutet: so für das Municipium Tungrorum (Tongeren) in der ersten Hälfte des 2. Jahrhunderts n. Chr. ${ }^{85}$, für Ulpia Noviomagus (Nijmegen) in der zweiten Hälfte des 2. Jahrhunderts n. Chr. ${ }^{86}$, wobei hier das genaue Aussehen der Ummauerung noch nicht geklärt ist, und für Aelia Augusta (Augsburg) in hadrianischer Zeit ${ }^{87}$. Allerdings

\footnotetext{
${ }^{79}$ Eines der spätesten Beispiele hierfür ist die Stadtmauer von Xanten - S. Leih, Die Colonia Ulpia Traiana und ihre Vorgängersiedlung - zur Genese einer römischen Stadt, in: G. Brands u. a. (Hrsg.), Rom und die Provinzen. Gedenkschrift Heinz Gabelmann, BJb Beih. 53 (Mainz 2001) 173-177. Hierbei spricht die geringe Mauerstärke eher für einen Repräsentationsbau, J.-S. Kühlborn, Einige Beobachtungen zum Bau der Stadtmauer der Colonia Ulpia Traiana, BJb 187, 1987, 412-494, der als Machtdemonstration an der Grenze des Reiches verstanden werden könnte; s. U. Heimberg - A. Rieche, Colonia Ulpia Traiana. Die römische Stadt. Planung, Architektur, Ausgrabung (Köln 1998).

${ }^{80}$ s. dazu die Argumentation E. Swobodas bei der Datierung der Aguntiner Mauer nach historischen Überlegungen: Swoboda 1935, 47-50.

${ }^{81}$ Th. Fischer, Beispiele zur Entstehung römischer Städte in den Nordwestprovinzen, in: Precht 2001, 11-16; H. Hurst, Civic space at Glevum, in: Hurst 1999, 152-160; J. Crickmore, Romano-British Urban Defences, BAR 126 (Oxford 1984); noch um 213 n. Chr. wird die Stadtmauer von York anlässlich der Erhebung zur Colonia und Hauptstadt der Provinz Britannia ausgebaut: P. Ottaway, York: The study of late Roman Colonia, in: Hurst 1999, 136-150.

${ }_{82}$ Aventicum wird um 70 n. Chr. zur Colonia: R. Frei-Stolba, Die römische Schweiz: Ausgewählte staats- und verwaltungsrechtliche Probleme im Frühprinzipat, in: ANRW II 5, 1 (Berlin 1976) 384-403 und J. F. Drinkwater, Roman Gaul. The three provinces, 58 B.C. - A.D. 260 (Ithaca, NY 1983) 141-160. Die Ummauerung könnte als »Unterstreichung der Rolle als Hauptstadt« angesehen werden, so H. Bögli, Aventicum - Die Römerstadt und das Museum (Brugg 1991) 47. Für das nahe gelegene Augusta Raurica lässt sich keine eindeutige Aussage treffen, da auch das Gründungsdatum umstritten ist, dazu zuletzt T. TomasevicBuck, Augusta Raurica - Probleme, Anregungen, Neufunde, SchrVLM 7 (Bregenz 2003). Auffallend ist bei beiden Städten die Ummauerung eines weiten, nicht besiedelten Gebiets, M. Schaub, Das Osttor und die Stadtmauer von Augusta Raurica (Grabung 1993 .52), JBerAugst 15, 1994, 73-132.

${ }^{83}$ Drinkwater (Anm. 82) 141-160 zu Köln und Xanten. S. S. Frere dagegen nimmt an, dass hier die Repräsentation, nicht der »praktische Nutzen« der wesentliche Grund für den Bau der Ummauerung war: S. S. Frere, British Urban Defences in Earthwork, Britannia 15, 1984, 63-74.

${ }^{84}$ Für Köln um 50 n. Chr.: H. Hellenkemper, The Roman Defences of Cologne - Colonia Claudia Ara Agrippinensium, in: Maloney - Hobley 1983, 20-28; Xanten in trajanischer Zeit: zuletzt Heimberg - Rieche (Anm. 79).

${ }^{85}$ Zum Munizipialrecht A. Vanderhoeven, Das vorflavische Tongeren: Die früheste Entwicklung der Stadt anhand von Funden und Befunden, in: Precht 2001, 157-176.

${ }^{86}$ J. E. Bogaers, Civitates und Civitas-Hauptorte in der nördlichen Germania Inferior, BJb 172, 1972, 312-318; bei H. Van Enckevort - J. Thijssen, Der Hauptort der Bataver in Nijmegen im 1. Jh. n. Chr., in: Precht 2001, 88-110 wird angenommen, dass die Errichtung der Stadtmauer um 160 n. Chr. auch schon vor der Erhebung zum Municipium möglich wäre.

${ }^{87}$ M. Schaub, Topographie und Stratigraphie des römischen Augsburg aufgrund neuer Ausgrabungen, in: Wamser 2002, 109-120; zuletzt: L. Bakker, Vom Militärort zur Provinzhauptstadt, in: Archäologie in Bayern - Fenster zur Vergangenheit (Regensburg 2006) 200-202, wobei hier ein Zusammenhang mit städtischer Repräsentation wieder bestritten und der Bau um $170 \mathrm{n}$. Chr. datiert wird. Anders S. Ortisi, Die Stadtmauer der rätischen Provinzhauptstadt Aelia Augusta - Augsburg, Augsburger Beiträge zur Archäologie 2, 2001, 76-78, wo neben später hinzutretenden fortifikatorischen Gedanken die städtische Repräsentation als ursprünglicher Grund für den Mauerbau angeführt wird (Datierung des Baubeginns in die 60-iger Jahre des 2. Jhs. n. Chr.).
} 
bleiben die meisten bekannten municipia ohne Befestigungsmauer oder erhalten eine solche erst deutlich später $^{88}$. So etwa Aquincum (Budapest), das 124 n. Chr. zum Municipium wird, seine Ummauerung aber erst Ende des 2. Jahrhunderts n. Chr. erhält, als die Stadt schon den Status einer Colonia (194 n. Chr.) innehatte ${ }^{89}$. Die Errichtung einer Stadtmauer in Zusammenhang mit der Änderung des rechtlichen Status der Stadt bedeutet nicht automatisch, dass die Ummauerung nun ausschließlich repräsentative Zwecke erfüllte. So zeugt z. B. der angelegte Doppelgraben ${ }^{90}$ in Aelia Augusta (Augsburg) durchaus vom fortifikatorischen Wert der Anlage. Eine klare Trennung von Repräsentation und Wehrbau scheint ohnehin schwer möglich ${ }^{91}$, da ein Mauerring immer Schutz gegen etwaige Angriffe bedeutet.

Auch für das römische Aguntum scheint es bei momentanem Forschungsstand möglich, die Erhebung der Stadt zum Municipium unter Claudius als Auslöser für eine in gewissem Sinne >repräsentativereく Bautätigkeit anzusehen. Dafür spricht auch die geographisch und verkehrstechnisch günstige Lage, die wirtschaftlichen Aufschwung und einen gewissen Reichtum der Stadt schon zu Beginn der römischen Einflussnahme ermöglicht, wie die frühen römischen Steinbauten in Aguntum bezeugen: etwa die Therme des beginnenden 1. Jahrhunderts n. Chr. und das bald darauf mit einer ersten Phase entstandene Atriumhaus. Vor allem dieses zeugt von großem Wohlstand und dem Bedürfnis, das italische Bürgertum mit entsprechenden Bauten zu repräsentieren ${ }^{92}$. So könnte es sich auch beim Bau der Aguntiner Stadtmauer um ein Projekt handeln, das in italischer Tradition das Wesen der Siedlung als Stadt repräsentieren sollte.

Ein vollkommen anderes Erklärungsmodell für die Aguntiner Stadtmauer, das in der Forschungsdiskussion $\mathrm{zu}$ finden ist ${ }^{93}$, soll hier nicht unkommentiert bleiben. Es handelt sich um die Interpretation des Mauerzuges als Hochwasserschutz, was angesichts der im Gebiet von Aguntum häufigen Überschwemmungskatastrophen möglich erscheint und die kleinen und somit leicht verschließbaren Tore erklären würde. Allerdings fehlen vergleichbare römische Anlagen völlig ${ }^{94}$, und es ist für das antike Aguntum noch ungeklärt, woher eine eventuelle Hochwasserbedrohung anzunehmen wäre, da sich die Geländebedingungen und der Verlauf des infrage kommenden Debantbaches aufgrund der mehrfachen Übermurungen in den letzten 2000 Jahren stark verändert haben. Es sind bisher auch aus den Grabungen keine deutlichen Indizien für eine Hochwasserschutzmauer hervorgegangen, womit eine derartige Deutung sehr unwahrscheinlich bleibt.

Der Schwachpunkt jeder funktionalen Interpretation der Aguntiner Stadtmauer bleibt zum momentanen Zeitpunkt der Forschungsstand. So ist es nach wie vor unklar, ob das Bauprojekt Vollendung fand oder nur Teile der geplanten Ummauerung errichtet wurden. Im Nordteil verläuft die Stadtmauer ab einem gewissen Punkt zur Gänze im Murenschotter, wo sie von Erich Swoboda auch nicht mehr festgestellt werden konnte. Die >schöne Abmauerung « im Süden spricht für ein Ende der Mauer an dieser Stelle, aber auch hier ist letztendlich noch keine vollkommene Sicherheit gegeben ${ }^{95}$. Weiters ist es, wie bereits erwähnt, noch nicht gesichert, ob im ursprünglichen Bauplan der Mauer eine große Toranlage vorgesehen war.

\footnotetext{
${ }^{88}$ Neben den norischen Municipia ist hier Arae Flaviae (Rottweil) zu nennen, das sich aus einem Kastellvicus entwickelte und wohl um 80-120 n. Chr. den Municipialstatus verliehen bekam, aber ohne Ummauerung blieb; zuletzt: Gairhos (Anm. 76) 195-197. Auch für Forum Hadriani wird eine Ummauerung erst deutlich nach Verleihung des Stadtrechts (spätestens $160 \mathrm{n}$. Chr.) angenommen: Bogaers (Anm. 86) 318-326. Gleiches gilt für das Anfang des 4. Jhs. n. Chr. ummauerte Scarbantia, das schon in den 70-iger Jahren des 1. Jhs. n. zum Municipium wurde: K. Sz. Poczy, Städte in Pannonien (Budapest 1976) $24-33$.

${ }^{89}$ Zum rechtlichen Status von Aquincum: Poczy (Anm. 88) 41-55.

${ }^{90}$ S. Ortisi, Vallum cum turribus. Zur Westumwehrung der rätischen Provinzhauptstadt Aelia Augusta/Augsburg, in: Wamser 2002, $145-156$.

${ }_{91}$ Dazu auch Ortisi (Anm. 87) 76-78. Anders F. Kolb, der die Errichtung mancher Befestigungsbauten als »oft nicht mehr als eine Verzierung der Stadt« ansieht: F. Kolb, Die Stadt im Altertum (München 1984) 180-203.

${ }^{92}$ Dass der Bautyp des Atriumhauses für die kalten Monate dieser Breitengrade nachteilig war, wurde den Bewohnern bald klar, weshalb offene Räume verschlossen und Hypokaustenanlagen eingebaut wurden: Tschurtschenthaler 2002, 1071-1089.

${ }_{93}$ Wotschitzky (Anm. 38) 119-123 und Alzinger (Anm. 39) 49.

${ }^{94}$ Abgesehen von der Möglichkeit einer Hochwasserverbauung in Celeia, die bislang aber auch nicht gesichert ist: I. Lazar, Celeia, in: M. Sašel Kos - P. Scherrer (Hrsg.), Die autonomen Städte in Noricum und Pannonien. Noricum, Situla 40 (Ljubljana 2002) $71-101$.

${ }^{55}$ Dazu auch Miltner 1953b, 32-34, wo das Südende als vorläufiges Südende und nicht als gänzlich gesichertes Mauerende angesprochen wird, da die Grabung 5,5 m südlich dieses »Endes« abgebrochen werden musste, weil man dem Damm des Debantbaches schon zu nahe war
} 
Zusammenfassend betrachtet kann die Aguntiner Stadtmauer aus rechtlichen Gründen erst nach der Verleihung des Munizipialrechts durch Kaiser Claudius erbaut worden sein, war aber, wie aus der Auswertung des archäologischen Befundes hervorgeht, zu Beginn des 2. Jahrhunderts n. Chr. schon weitgehend fertiggestellt. Somit datiert der Mauerbau in die zweite Hälfte des 1. Jahrhunderts n. Chr., wobei die Frage nach den Hintergründen eines derartig aufwendigen Bauprojekts aufgrund der in diesem Bereich noch ausstehenden, ebenso aufwendigen modernen Feldforschung vorerst unbeantwortet bleiben muss.

\section{Fundkatalog}

\subsection{Glas $^{96}$}

Kat. 1

Abb. 17

Randfrgt. einer Rippenschale Form Isings $3 \mathrm{~b}-\mathrm{AR} 2.2$.

Dm: $10-18 \mathrm{~cm}$

Farbe: blaugrün (Rütti 570)

Datierung: 2. Hälfte 1. Jh. n. Chr. - 1. Hälfte 2. Jh. n. Chr.

Kat. 2

Abb. 17

Randfrgt. einer Rippenschale Form Isings $3 b$ - AR 2.2.

Dm: $13 \mathrm{~cm}$

Farbe: blaugrün (Rütti 570)

Datierung: 2. Hälfte 1. Jh. n. Chr. - 1. Hälfte 2. Jh. n. Chr.

\subsection{Feinkeramik ${ }^{97}$}

\section{Kat. 3}

Abb. 17

Bodenfrgt. eines Schälchens mit einer \Zierleiste unmittelbar über der Bodenauflage. Der Boden liegt flach, ohne Ansatz eines Standringes.

Dm: $6,2 \mathrm{~cm}$

Ton: keine erkennbare Magerung; grau (10YR 7/1-6/1); Überzug: dunkelgrau (10YR 5/1)

Vgl.: Ein ähnliches Stück findet sich bei R. Fleischer V. Moucka-Weitzel, Die Straßenstation Immurium - Moosham im Salzburger Lungau (Salzburg 1998) Taf. 25, 20.

Datierung: wohl ab der 2. Hälfte des 1. Jhs. n. Chr.

\subsection{Terra Sigillata $^{98}$}

Kat. 4

Abb. 19

Randfrgt. Form Consp. 34 mit Resten einer Barbotine-Verzierung (wohl eine Maske)

Dm: ?
Ton: gelb rötlich (5YR 7/6); Überzug: $\operatorname{rot}(2.5$ YR 4/8)

Datierung: spättiberisch - flavisch, eventuell auch später.

Kat. 5

Abb. 19

Randfrgt. Form Consp. 43.3.

Dm: $8 \mathrm{~cm}$

Ton: gelb rötlich (5YR 7/6); Überzug: $\operatorname{rot}(2.5 \mathrm{YR} 4 / 8)$

Datierung: 2. Hälfte 1. Jh. n. Chr. -1 . Hälfte 2. Jh. n. Chr.

Kat. 6

Abb. 21

4 Randfrgte., 3 Wandfrgte., 2 Bodenfrgte. eines Tellers Drag. $18 / 31$.

Rand-Dm: $31 \mathrm{~cm}$; Boden-Dm: 10,5 cm

Ton: rötlich (2.5YR 6/8); Überzug: $\operatorname{rot}(2.5 Y R \quad 4 / 8)$

Datierung: 2. Jh. n. Chr.

Kat. 7

Abb. 27

Wandfrgt. einer Reliefschüssel Drag. 37.

Ton: hell rötlich (5YR 6/4); Überzug: dunkelrot (10R 4/6)

Dekor: Herkules mit Hydra und Eierstab mit Quaste am Stäbchenende. Zuordenbar der Werkstatt des MERCATO in La Graufensenque.

Vgl.: in Noricum: P. Karnitsch, Sigillata von Iuvavum (Salzburg). Die reliefverzierte Sigillata im Salzburger Museum Carolino Augusteum (Salzburg 1971) Taf. 21, 9.

Datierung: letztes Viertel 1. Jh. n. Chr.

\subsection{Lampen $^{99}$}

\section{Kat. 8}

Abb. 19

Dreieckig geformter Lampengriff der Form Loeschcke III mit vegetabiler Verzierung und roter Engobe

Ton: bräunlich (7.5YR 7/4); Überzug: dunkelrot (10R 5/6)

Datierung: 1. Jh. - Anfang 2. Jh. n. Chr.

${ }^{96}$ Die Formbestimmung bezieht sich auf C. Isings, Roman Glass from dated Finds (Groningen 1957) und B. Rütti, Die römischen Gläser von Augst und Kaiseraugst, FiA 13 (Augst 1991) (AR), wobei die Farbe des Glases nach der bei Rütti wiedergegebenen Farbtafel bestimmt wurde.

${ }^{97}$ Farbbestimmung nach Munsell Soil Colour Charts (Revised Edition, Baltimore 1994).

${ }_{98}$ Farbbestimmung nach Munsell (Anm. 97). Die Formen werden nach E. Ettlinger u. a., Conspectus Formarum Terrae Sigillatae italico modo confectae, Materialien zur römisch-germanischen Keramik 10 (Bonn 1990) bzw. H. Dragendorff, Terra Sigillata, BJb 96/97, 1895/1896, 18-155 angegeben.

${ }_{99}$ Farbbestimmung nach Munsell (Anm. 97). Die Form wird nach S. Loeschcke, Lampen aus Vindonissa. Ein Beitrag zur Geschichte von Vindonissa und des antiken Beleuchtungswesens (Zürich 1919) wiedergegeben. 


\subsection{Teller und Platten ${ }^{100}$}

\section{Kat. 9}

1 Rand- und 1 Bodenfrgt eines engobierten Tellers

Rand-Dm: 26,9 cm; Boden-Dm: 19,4 cm

Ton: leicht glimmerhältig, mit kleinen Steinchen gemagert (Quarz?); gelblich (5YR 6/8); Engobe: hellrotorange (2.5YR $5 / 8-6 / 8)$

Datierung: ?

\section{Kat. 10}

Abb. 21

1 Rand- und 1 Bodenfrgt. eines engobierten >Soldatentellers Rand-Dm: $35 \mathrm{~cm}$; Boden-Dm: 31,6 cm

Ton: wenig glimmerhältig, mit wenigen kleinen Steinchen gemagert (Quarz?); braungrau (10YR 5/3); Engobe: bräunlich $\operatorname{rot}(5 \mathrm{YR} 3 / 3)$

Datierung: Sehr häufige Form, die vom Ende des 1. Jhs. n. Chr. bis in das 3. Jh. n. Chr. vorkommt.

\subsection{Gebrauchskeramik ${ }^{101}$}

\section{Kat. 11}

Abb. 19

3 Randfrgte., 17 Wandfrgte. eines reduzierend gebrannten Kruges mit Henkelansätzen

Rand-Dm: $9 \mathrm{~cm}$

Ton: stark glimmerhältig, nur stellenweise porös (lagerungsbedingt?); grau - dunkelgrau (10YR 6/1-4/1)

Vgl.: Nur in Aguntum sicher belegt: S. Schoitsch, Die keramischen Kleinfunde aus der Therme Aguntums (Ausgrabungen 1964-1974) (Diss. Universität Wien 1976) Taf. 44, 397. Datierung: ?

\section{Kat. 12}

Abb. 19

Wandfrgt. eines reduzierend gebrannten Deckels; verziert mit längsrechteckigen Kerbreihen und Rillen.

Ton: leicht porös; grau - dunkelgrau (10YR 6/1-4/1)

Datierung: ?

\section{Kat. 13}

Abb. 19

9 Wandfrgte. eines reduzierend gebrannten Topfes; verziert mit verdoppelten Wellenbändern und längsrechteckigen Kerbreihen.

Ton: wenig glimmerhältig, leicht porös; grau - dunkelgrau (10YR 6/1-4/1)

Datierung: ?

\section{Kat. 14}

Abb. 18

Randfrgt. eines reduzierend gebrannten Topfes

Dm: $30,4 \mathrm{~cm}$

Ton: wenig glimmerhältig, sehr porös; dunkelgrau - schwarz (10YR 3/1-2/1)
Vgl.: Im norischen Raum sehr häufig belegt, zuletzt bei Gugl 2000, Taf. 30, 17.

Datierung: 1.-2. Jh. n. Chr.

Kat. 15

Abb. 18

1 Randfrgt., 6 Wandfrgte. eines reduzierend gebrannten Topfes mit Wellenbändern und Bogenkammstrich verziert.

Rand-Dm: $22,4 \mathrm{~cm}$

Ton: wenig glimmerhältig, sehr porös; dunkelgrau - schwarz (10YR 3/1-2/1)

Vgl.: Im norischen Raum belegbar, u. a. bei A. Kaltenberger, Ausgrabungen St. Peter, Salzburg: II. Römerzeitliche lokale Gebrauchsware und mittelalterliche Keramik 1980-1995, ÖJh 67, 1998, Beibl. 244-484 Taf. 5, 29.

Datierung: wohl 1. Jh. n. Chr. - Anfang 2. Jh. n. Chr.

Kat. 16

Abb. 18

Randfrgt. eines reduzierend gebrannten Topfes

Dm: $17 \mathrm{~cm}$

Ton: wenig glimmerhältig, sehr porös; grau - dunkelgrau (10YR 6/1-4/1)

Vgl.: Im norischen Raum häufig belegt, u. a. Gugl 2000, Taf. 53, 16.

Datierung: 2. Jh. n. Chr.

Kat. 17

Abb. 18

Randfrgt. eines reduzierend gebrannten Topfes

Dm: $17 \mathrm{~cm}$

Ton: leicht porös; dunkelgrau - schwarz (10YR 3/1-2/1)

Vgl.: Im norischen Raum sehr häufig belegt, so Gugl 2000, Taf. 44, 90 .

Datierung: 1. -3 . Jh. n. Chr.

Kat. 18

Abb. 18

Randfrgt. eines reduzierend gebrannten Topfes

Dm: $14,4 \mathrm{~cm}$

Ton: leicht porös; grau - dunkelgrau (10YR 6/1-4/1)

Vgl.: Im norischen Raum sehr häufig belegt, u. a. Gugl 2000, Taf. 38, 20.

Datierung: 1.-3. Jh. n. Chr.

Kat. 19

Abb. 20

Randfrgt. eines reduzierend gebrannten Topfes

Dm: $21 \mathrm{~cm}$

Ton: sehr porös; dunkelgrau - schwarz (10YR 3/1-2/1)

Vgl.: Im norischen Raum sehr häufig belegt, u. a. Gugl 2000, Taf. 32, 25; 33, 50 .

Datierung: 1. Jh. n. Chr.

Kat. 20

Abb. 20

Randfrgt. eines reduzierend gebrannten Topfes

${ }^{100}$ Farbbestimmung nach Munsell (Anm. 97).

101 Farbbestimmung nach Munsell (Anm. 97). Der Glimmergehalt des Scherbens wird angegeben, wenn vorhanden. Ebenso wird eine allfällig vorhandene Magerung, es handelt sich dabei meist wohl um Quarzpartikel, angegeben, falls vorhanden. 
Dm: $20 \mathrm{~cm}$

Ton: wenig glimmerhältig, leicht porös; grau - dunkelgrau (10YR 6/1-4/1)

Vgl.: Bisher nur in Aguntum eindeutig belegt: S. Schoitsch, Die keramischen Kleinfunde aus der Therme Aguntums (Ausgrabungen 1964-1974) (Diss. Universität Wien 1976) Taf. 58, 513-514.

Datierung: 1./2. Jh. n. Chr.

\section{Kat. 21}

Randfrgt. eines reduzierend gebrannten Topfes

Dm: $23 \mathrm{~cm}$

Ton: wenig glimmerhältig, porös; grau - dunkelgrau (10YR 6/1-4/1)

Vgl.: In Aguntum und südlich davon belegt: A. Waldner, Römerzeitliche Fundstellen im Brixner Becken (Südtirol); Stufels 12-Mitterutzner, Stufels 10B, Stufels Russo (Mag. Univeristät Wien 2003) Taf. 24, 5.

Datierung: wohl 2. Jh. n. Chr.

\section{Kat. 22}

Randfrgt. eines reduzierend gebrannten Topfes

Abb. 20

Dm: $15 \mathrm{~cm}$

Ton: glimmerhältig, keine Poren; grau - dunkelgrau (10YR $6 / 1-4 / 1)$

Vgl.: Im norischen Raum häufig belegt, zuletzt: R. Jernej Ch. Gugl, Virunum. Das römische Amphitheater. Die Grabungen 1998-2001 (Klagenfurt 2004) Taf. 6, 114.

Datierung: 1./2. Jh. n. Chr.

\section{Kat. 23}

Randfrgt. eines reduzierend gebrannten Topfes

Dm: $18,8 \mathrm{~cm}$

Ton: wenig glimmerhältig, sehr porös; dunkelgrau - schwarz (10YR 3/1-2/1)
Vgl.: Im norischen Raum häufig belegt, u. a. bei A. Kaltenberger, Ausgrabungen St. Peter, Salzburg: II. Römerzeitliche lokale Gebrauchsware und mittelalterliche Keramik 1980-1995, ÖJh 67, 1998, Beibl. 244-484 Taf. 13, 78.

Datierung: 2. Hälfte 1.-2. Jh. n. Chr.

\section{Kat. 24}

Abb. 22

Randfrgt. eines reduzierend gebrannten Topfes

Dm: $14 \mathrm{~cm}$

Ton: wenig glimmerhältig, porös; dunkelgrau - schwarz (10YR 3/1-2/1)

Vgl.: Im norischen Raum häufig belegt, zuletzt: R. Jernej Ch. Gugl, Virunum. Das römische Amphitheater. Die Grabungen 1998-2001 (Klagenfurt 2004) Taf. 10, 100.

Datierung: wohl 1. Jh. n. Chr.

\section{Kat. 25}

Abb. 22

Bodenfrgt. eines reduzierend gebrannten Topfes

Dm: $11 \mathrm{~cm}$

Ton: wenig glimmerhältig, sehr porös; graubraun (10YR 4/36/3)

Vgl.: Sehr häufige Bodenform, die keine nähere Einordnung ermöglicht.

\section{Kat. 26}

Abb. 22

1 Randfrgt., 1 Wandfgrt. eines reduzierend gebrannten Topfes, nachträglich Hitze ausgesetzt oder oxidierend nachgebrannt. Rand-Dm: 34 cm

Ton: stark glimmerhältig, mit kleinen Steinchen gemagert (Quarz?), sehr porös; grau - dunkelgrau (10YR 6/1-4/1), an der Außenseite hellbraun (10YR 6/6-6/8)

Vgl.: Vergleichsweise selten belegte Form, zuletzt bei R. Fleischer - V. Moucka-Weitzel, Die Straßenstation Immurium Moosham im Salzburger Lungau (Salzburg 1998) Taf. 72, 1. Datierung: 2. Jh. n. Chr.

\section{Abgekürzt zitierte Literatur}

Alzinger 1959

Alzinger 1960

Alzinger 1985

Ciurletti 2002

Gug1 2000

Hurst 1999

Maloney - Hobley 1983

Miltner 1953

Miltner 1953b
W. Alzinger, Aguntum. Vorläufiger Bericht über die Grabungen in den Jahren 1955 bis 1957, ÖJh 44, 1959, Beibl. 75-140.

W. Alzinger, Stadtmauerprobleme, ÖJh 45, 1960, 4-35.

W. Alzinger, Aguntum und Lavant (Dölsach 1985).

G. Ciurletti, Eine Stadt an der Via Claudia Augusta: Tridentum. Jüngste Grabungen und Entdeckungen, in: V. Galliazo (Hrsg.), Via Claudia Augusta. Eine Straße am Ursprung Europas: Hypothesen, Probleme, Perspektiven (Feltre 2002) 177-191.

C. Gugl, Archäologische Forschungen in Teurnia. Die Ausgrabungen in den Wohnterrassen 1971-1978. Die laténezeitlichen Funde vom Holzer Berg, SoSchrÖAI 33 (Wien 2000).

H. Hurst, The Coloniae of Roman Britain. New studies and a review, JRA Suppl. 36 (Portsmouth 1999) 88-100.

J. Maloney - B. Hobley (Hrsg.), Roman Urban Defences in the West. A Review of current Research on Urban Defences in the Roman Empire with special Reference to the Northern Provinces, based on Papers presented to the Conference on Roman Urban Defences held at the Museum of London on 21-23 March 1980, CBA Research Report 51 (London 1983).

F. Miltner, Aguntum. Vorläufiger Bericht über die Ausgrabungen 1950-1952, ÖJh 40, 1953, 93-156.

F. Miltner, Grabung Aguntum 1953, PAR 3, 1953, 32-34. 
Miltner 1955

Ploner 1912

Precht 2001

Swoboda 1935

Tschurtschenthaler 2002

Walde 2002

Wamser 2002
F. Miltner, Aguntum. Vorläufiger Bericht über die Ausgrabungen 1953 und 1954, ÖJh 42, 1955, 72-96.

I. Ploner, Agunt - die alte Kelten und Römerstadt bei Lienz in Tirol und Professor Ploners Ausgrabungen daselbst (Lienz 1912).

G. Precht - N. Zieling (Hrsg.), Genese, Struktur und Entwicklung römischer Städte im 1. Jh. n. Chr. in Nieder- und Obergermanien, Xantener Berichte 9 (Mainz 2001).

E. Swoboda, Aguntum. Ausgrabungen bei Lienz in Osttirol 1931-1933, ÖJh 29, 1935, 5-102.

M. Tschurtschenthaler, Municipium Claudium Aguntum. Das Atriumhaus im Licht der aktuellen Forschungen, in: Archäologie der Römerzeit in Südtirol I (Bozen 2002).

E. Walde, Aguntum, in: M. Sašel Kos - P. Scherrer (Hrsg.), Autonome Städte in Noricum und Pannonien. I: Noricum, Situla 40 (Ljubljana 2002).

L. Wamser - B. Steidl (Hrsg.), Neue Forschungen zur römischen Besiedlung zwischen Oberrhein und Enns, Kolloquium Rosenheim 14.-16. Juni 2000 (Remshalden-Grunbach 2002).

Mag. Martin Auer

Institut für Archäologien, Klassische und Provinzialrömische Archäologie, Universität Innsbruck, Langer Weg 11 , A-6020 Innsbruck

E-Mail: martin.auer@uibk.ac.at

Abbildungsnachweis: Abb. 1: Institut für Archäologien Innsbruck, Grabungstechnik 2007; Abb. 2: Archiv ÖAI, AguFON2095; Abb. 3: Verf.; Abb. 4: Archiv ÖAI, Agu 2a/52/22; Abb. 5: nach Miltner 1953, Abb. 57; Abb. 6: nach Swoboda 1935, Abb. 4; Abb. 7: nach Alzinger 1960, Abb. 22; Abb. 8: Archiv ÖAI, Agu I2608; Abb. 9: Archiv ÖAI, Agu I1294; Abb. 10: Verf. auf Grundlage des Gesamtplans des Instituts für Archäologien Innsbruck, Grabungstechnik 2007; Abb. 11: Institut für Archäologien Innsbruck, Dia 1153/94; Abb. 12: Verf.; Abb. 13: Archiv ÖAI, Agu FON2810; Abb. 14: Institut für Archäologien Innsbruck Dia 629/94; Abb. 15-22. 24. 25. 27: Verf.; Abb. 23: Archiv ÖAI, Agu I9688/6; Abb. 26: Institut für Archäologien Innsbruck, Dia 1246/94. 